\title{
Grafitos sobre cerámica del puticuli de la calle Cabo Verde de Mérida (España). Nuevos datos sobre la cotidianidad Emeritense en el siglo I d. C.
}

\author{
Graffiti on pottery from puticuli of Cabo Verde street \\ in Mérida, Spain. New data about the Emeritensis daily \\ life in the first century $A D$
}

\author{
LUIS Ángel Hidalgo MARTíN ${ }^{* * *}$ \\ MacARena Bustamante ÁlvareZ ${ }^{* *}$ \\ Carmen Pérez Maestro*
}

\begin{abstract}
RESUMEN
ABSTRACT

Damos a conocer un repertorio de grafitos grabados sobre cerámica y procedentes de una reciente intervención arqueológica en la capital de la Lusitania, Augusta Emerita (Mérida, España). Este conjunto, que supera los cien individuos, nos ha permitido valorar en especial la antroponimia emeritense en un soporte cotidiano -la cerámica- y en un contexto arqueológico muy concreto, un vertido cultual en un puticuli o fosa común localizada en el sector noreste de la actual ciudad de Mérida. Con este trabajo pretendemos que la valoración epigráfica se imbrique con un estudio tipológico y contextual de las piezas que le sirven de
\end{abstract}

*** Consorcio «Ciudad Monumental Histórico-Artística y Arquelógica de Mérida». Calle Reyes Huertas, 5, 06800-Mérida (España). Ihidalgo@ consorciomerida.org

Instituto de Arqueología de Mérida -CSIC-. Plaza de España, 15, 06800-Mérida (España). macarena.bustamante@iam.csic.es

Arqueóloga-Investigadora independiente. Calle Duque de Salas 8, 06800-Mérida (España). mamenarqueo@ hotmail.com 
soporte, siendo este tipo de análisis en el espacio que nos ocupa una novedad.

PALABRAS CLAVE:

Grafitos sobre cerámica, precocción, postcocción, terra sigillata, lucernas, epigrafía romana, Augusta Emerita.

\section{KEYWORDS:}

Graffiti on pottery, precooking, postcooking, terra sigillata, lamps, roman epigraphy, Augusta Emerita.

Recibido el 7 de junio de 2012. Aceptado el 5 de agosto de 2012

\section{INTRODUCCIÓN}

En las siguientes páginas analizamos un conjunto de ciento veinte y dos piezas cerámicas grafitadas. Todos los ejemplares proceden de una intervención arqueológica realizada en el año 2004 con motivo de la construcción de un nuevo edificio en lo que hasta el momento había sido un cuartel de artillería, sito en la calle Cabo Verde de la actual capital extremeña. ${ }^{1}$ La dinámica ocupacional del espacio, con un fuerte hiato desde época romana hasta el siglo XX, permitió un registro limpio y carente de procesos post-deposicionales traumáticos para los contextos que ahora pasamos a valorar.

\section{EL PUTICULI DE LA CALLE CABO VERDE}

Las piezas que concretamente valoramos proceden del relleno de una gran fosa excavada en la roca geológica e interpretada como puticuli o fosa común de enterramiento, ${ }^{2}$ de ahí el interés creciente de este conjunto con altos tintes votivos.

Esta fosa estaba delimitada, al menos, por dos cortes laterales realizados en la roca con un perfil predominantemente vertical. Morfológicamente es de planta oval y perfil en forma de $U$, con unas dimensiones conocidas ${ }^{3}$ de $43,47 \mathrm{~m}$. de longitud, $29,62 \mathrm{~m}$. de anchura máxima y 13,90 m. de mínima, y una profundidad aproximada de 4,5 m. Su aparente improvisación nos hace pensar que estamos ante una fosa para extracción de dioritas a propósito de los primeros esfuerzos constructivos de la ciudad, siendo a posteriori colmatada con los elementos que pasamos a comentar y que, sin lugar a dudas, hablan de una gestión de los residuos poco organizada en los primeros tiempos de la colonia y fuera del perímetro urbano emeritense. ${ }^{4}$

1 Esta intervención arqueológica tiene el no de registro 8067 del Depto. de Documentación del Consorcio de la Ciudad Monumental Histórico-Artística y Arqueológica de Mérida.

2 PÉREZ MAESTRO, C., «El puticuli de Augusta Emerita». Korpergräber Des 1-3 Jahrhunderts in der römischen welt. Internationales colloquium (Frankfurt am Main, 2004). Frankfurt am Main, 2007, pp. 291-304.

${ }^{3}$ Las dimensiones totales no pudieron ser documentadas debido a que la intervención arqueológica se limitó al espacio donde iba a ser construido el nuevo edificio.

4 ACERO PÉREZ, J., «Augusta Emerita», en «La gestión de los residuos urbanos en Hispania (Xavier Dupré Raventós (1956-2006). In memoriam), Anejos de AespA, LX, (2011), pp. 157-180. 
Estratigráficamente son varios los niveles documentados -UU.EE. 21, 22, 34, $56,65,66,94$ o 124-que nos permiten reconstruir la dinámica de vertido en dicha fosa. Todos los estratos presentan una composición uniforme: materiales orgánicos -cenizas, restos antracológicos, malacofauna, fauna terrestre o restos óseos humanos-, así como materiales inorgánicos —cerámica, vidrio, metal, industria ósea y un fuerte repertorio de decoración parietal- conforman el mayor conjunto.

De todos los objetos muebles localizados nos interesa en este trabajo las cerámicas con grafitos, tanto los alfabéticos como los que no lo son, de tipología muy variada y de cronología muy concreta que nos lleva a los primeros flavios. Entre las categorías representadas encontramos tanto vajilla de mesa - sigillatas gálicas, hispánicas y paredes finas locales-como un interesante repertorio de cerámica común de mesa y de cocina, que nos hablan de un vertido aleatorio.

Para ajustar la cronología hemos utilizado las múltiples variables, siendo la información más precisa la aportada por las sigillatas sudgálicas e hispánicas. Uno de los fósiles cronológicos utilizados para determinar esta cronología son las parópsides 35 y 36 (servicio A) con decoración a barbotina de hojas de agua. Estas piezas inician su desarrollo en momentos finales de Nerón, ${ }^{5}$ alzándose como el servicio de época flavia por antonomasia. ${ }^{6}$ Este hecho unido a una serie de formas decoradas, como las formas Drag. 37 , que inciden en un momento flavio nos permiten hablar de esta época. Además, la muy elevada aparición de cerámica marmorata, también reafirmaría la cronología que ahora proponemos. ${ }^{7}$

Resultó significativa la presencia de gran cantidad de pintura mural y estuco estando ausente otros restos constructivos como tegulae, ripios o testae que nos pudieran hablar de derrumbes previos. La pintura mural nos permite hablar del vertido de dos paneles, uno del III estilo -con sucesión de paneles monócromos -negros y rojos- así como con candelabros estilizados- así como otro del IV estilo - con restos de predelas caladas-.

Además de la cerámica, el material que resalta más fuertemente son los restos humanos documentados - un total de sesenta y cuatro individuos- dispuestos en conexión anatómica pero sin ordenación alguna. Esta disposición nos permite hablar de vertedero pero a la misma vez de fosa común de restos humanos. El hecho de que únicamente se documenten inhumaciones (en una época en que el rito predominante en Emerita era la incineración) con los individuos en posturas tan inusuales y forzadas, con depósitos funerarios en contadas ocasiones (únicamente diez de los individuos poseían algún elemento de ajuar o depósito), ausentes en su gran mayoría de estructuras funerarias o en su defecto de algún tipo de cubierta, indica que estamos en un área donde se enterraban y «tiraban» a los in-

${ }^{5}$ GENIN, M. (ed.), La Graufesenque (Millau, Aveyron). Sigillées lisses et autres productions, Santander, 2007, p. 307.

6 VERNHET, A., "Création flavienne de six services de vaiseelle à la Graufesenque», Figlina, 1, (1976), pp. 13-27.

7 PÉREZ MAESTRO, C., "Análisis de la terra sigillata marmorata aparecida en un vertedero de época altoimperial en Mérida». Merida excavaciones Arqueológicas. Memoria, 7, (2004), pp. 361-368. 
dividuos de los sectores más bajos de la sociedad. Éstos, carentes de medios económicos necesarios para adquirir una sepultura, quedaban relegados a fosas comunes (puticuli). Estos pudrideros dispuestos en culinae o áreas de suelo público eran clasificados como loca publica, propiedad de todo el pueblo y designados para el uso de todos. ${ }^{8}$

\section{LOS GRAFITOS DE LA CERÁMICA DEL PUTICULI}

El corpus de grafitos estudiado que presentamos se organiza en un primer nivel de clasificación, dividido en dos grandes grupos dependiendo del momento en que se grabaron las incisiones, antes o después de la cochura: Grafitos precocción / Grafitos postcocción.

Los primeros constituyen un único bloque compuesto por 15 piezas de idéntica tipología la mayor parte del conjunto: lucernas en cerámica local de acabado irisado; resultando además su contenido epigráfico muy homogéneo (núm. 1-15). En cambio, los segundos, los grafitos postcocción (núm. 16-122), reúnen un variado abanico de soportes cerámicos con textos y signos heterogéneos que hemos optado por dividir primero en dos grandes conjuntos: los que tienen una lectura epigráfica, por un lado (núm. 16-88), y los que hemos interpretado como signos o símbolos no alfabéticos, por otro (núm. 89-122).

En un nivel inferior, hemos seguido una ordenación exclusivamente acorde con los tipos y formas de los soportes cerámicos. Aquí hemos tenido en cuenta en primer lugar el factor cronológico de la fabricación de los soportes. Así, se presentan, por este orden, las cerámicas locales de acabado irisado ( $n$ 16) / paredes finas (núm. 89-91), la terra sigillata itálica (no 17), la terra sigillata gálica (núm. 18-50 y 92-108), la terra sigillata hispánica (núm. 51-81 y 109-120) y, por último, la cerámica común (núm. 82-88 y 121-122). Esta última tipología al final de la exposición por su mayor imprecisión temporal (Tabla 2).

Y dentro de cada uno de los tipos cerámicos enumerados hemos secuenciado los grafitos de acuerdo a las formas de los soportes, iniciando la relación por el número de forma más bajo y acabando por el más alto. Este último criterio solo ha sido aplicado a los conjuntos de grafitos sobre las sigillatas gálicas e hispánicas, dado su elevado número de piezas, que constituyen a la postre el grueso del corpus (Tabla 2).

\subsection{Grafitos precocción}

En este apartado analizamos quince lucernas que presentan incisiones realizadas en momentos previos a la termoalteración sufrida por la cerámica durante la

8 PÉREZ MAESTRO, C., El puticuli de Augusta Emerita... 
cocción. Este conjunto supone el 12,3 \% del total de piezas estudiadas. Funcionalmente estas piezas las asociamos a marcas productivas en la figlina que atienden a un pragmatismo aún no definido en estos ambientes manufactureros ${ }^{9}$ y que algunos autores lo simplifican al the artist's mood at the moment. ${ }^{10} \mathrm{En}$ el conjunto presentado sobresalen los sigilla grabados todos en la base de las lucernas de factura local, perfilándose el alfarero $L \cdot F \cdot O$ como el más representativo en estos momentos; ${ }^{11}$ por lo que este contexto nos ha ayudado a esclarecer cronológicamente la dinámica productiva local. También encontramos otras iniciales que identificarían a alfareros tal vez con sus duo o tria nomina $(C \cdot L, I \cdot C \cdot G, F \cdot O \cdot F, M L$, NIC ?), ${ }^{12}$ así como un nominal desarrollado como lulius.

1. Lucerna. Perfil casi completo de lucerna en cerámica local de acabado irisado, forma Dr. 11. Sigillum precocción en su base, realizado a mano alzada. Altura: 0,6 cm. Lectura: $C(--) \cdot L(---)$. La interpunción es un punto.

2. Lucerna. Fragmento de base e infundibulum de una lucerna en cerámica local de acabado irisado, posible forma Dr. 9. Sigillum precocción en su base, realizado a mano alzada. Altura: 0,7 cm. Lectura: C(- - -) · L(- - -). Interpunción circular.

3. Lucerna. Fragmento de base una lucerna en cerámica local de acabado irisado, forma indeterminada. Sigillum precocción en su base, realizado a mano alzada. Altura:0'8 cm. Lectura: C(- - ) · L(- - -). La interpunción es un punto.

4. Lucerna. Fragmento de base de una lucerna en cerámica local de acabado irisado. Sigillum precocción en su base, realizado a mano alzada. Altura: 0,8 cm. Lectura: $C(---) \cdot L(--)$. Interpunción circular.

5. Lucerna. Fragmento de base e infundibulum de lucerna, posible forma Dr. 9. Sigillum precocción en su base, realizado a mano alzada. Altura: 0,9 cm. Lectura: L(- - -) · F(- - -) · O(- - -). Las marcas de separación son puntos.

6. Lucerna. Fragmento de base y pared de lucerna en cerámica local de acabado irisado. Sigillum precocción en su base, realizado a mano alzada. Altura: 0,6 cm. Lectura: L(- - -) · F(- - ) · O(- - ). Interpunción circular.

7. Lucerna. Fragmento de base de lucerna en cerámica local de acabado irisado, forma indeterminada. Sigillum precocción en su base, realizado a mano alzada. Altura: 0,8 cm. Lectura: $L(---) \cdot F(--)[\cdot O(---)]$. Interpunción circular.

9 Para profundizar más sobre el tema ver FÜLLE, G., «The internal organization of the Arretine Terra Sigillata industry: problems of evidence and interpretation», Journal of Roman Studies, 87, (1997), pp. 111-115.

10 BEAZLEY, J.D., Potter and painter in Ancient Athens, Londres, 1994, p. 33.

11 Cuya producción se ha localizado en los vertederos de la c/Constantino (ver RODRÍGUEZ MARTíN, G., «Materiales de un alfar emeritense: paredes finas, lucernas, sigillatas y terracotas», Cuadernos Emeritenses, 11, Mérida, 1996, p. 131).

12 De estos seis sigilla localizados sólo tres (NIC, C.L y L.F.O) eran conocidos en el panorama local, siendo los cuatro restantes totalmente inéditos. Para ver más sobre los productos locales, cf. RODRíGUEZ MARTíN, G., «Lucernas romanas del Museo Nacional de Arte Romano», Monografías Emeritenses, 7, Mérida, 2002, pp. 227-228. 
8. Lucerna. Fragmento de base e infundibulum de lucerna en cerámica local de acabado irisado, forma indeterminada. Sigillum precocción en su base, realizado a mano alzada. Altura: 0,6 cm. Lectura: $L(--) \cdot F(--) \cdot O(---)$. Interpunción circular.

9. Lucerna. Perfil casi completo de lucerna en cerámica local de acabado irisado, forma Dr. 9. Sigillum precocción en su base, realizado a mano alzada. Altura: 0,5 cm. Su lectura es algo incierta: $I(--) C(--$-) $G(-$ - - ).

10. Lucerna. Perfil casi completo en cerámica local de acabado irisado, forma indeterminada. Sigillum precocción en su base, realizado a mano alzada. Altura: 0,6 cm. Lectura: [- - ] ? F(- - -) · O(- - -) · F(- - -). Interpunción circular.

11. Lucerna. Fragmento de base de lucerna en cerámica local de acabado irisado. Sigillum precocción en su base, realizado a mano alzada. Altura: $1 \mathrm{~cm}$. Lectura: $M(---)[--$ ?]. Por otros ejemplos expuestos supra hay que pensar que el grafito estaría compuesto por una o dos letras más. Sin embargo, y por su similitud con el grafito siguiente ( $\mathrm{n}^{\circ}$ 12) proponemos la pérdida de una sola letra: $M(---)$ [L(- - )].

12. Lucerna. Fragmento de base de lucerna en cerámica local de acabado irisado. Sigillum precocción en su base, realizado a mano alzada. Altura: $0,5 \mathrm{~cm}$. Leemos solo dos letras, la fractura nos impide saber si habría alguna más: [- - - ? M(- -) L(- - -). Sin embargo, no lo consideramos probable, por analogía al anterior grafito ( $n^{\circ}$ 11). Por tanto, tendríamos dos lucernas ( $n^{\circ} 11$ y 12) con la misma marca bilítera de alfarero, $M L$.

13. Lucerna. Fragmento de la base de una lucerna en cerámica local de acabado irisado, forma indeterminada. Sigillum precocción en su base, realizado a mano alzada. Altura: $0,6 \mathrm{~cm}$. Lectura: NIC. La pieza tiene la fractura a la izquierda de la $N$, por lo que desconocemos si el grafito se conserva completo: [- - -] NIC(- -).

14. Lucerna. Fragmento de la base e infundibulum de lucerna en cerámica local de acabado irisado, forma Dr. 9. Sigillum precocción en su base, realizado a mano alzada Altura: 0,6 cm. Lectura: IVLIVS [-?].

15. Lucerna. Fragmento correspondiente a la mitad de la base de una lucerna de cerámica de pasta caolinítica y engobe rojizo externo. Sigillum precocción en su base, realizado a mano alzada. Altura: parte conservada $2 \mathrm{~cm}$. Lectura: $H$, de pies reforzados.

\subsection{Grafitos postcocción}

El otro gran grupo en el que hemos dividido el estudio son los grafitos realizados mediante el uso de estiletes y buriles una vez finalizada la pieza y, presumiblemente, una vez comercializada. Constituyen, por consiguiente, el único vestigio posible para rastrear a los consumidores. Principalmente, las piezas localizadas que portan estos elementos suelen ser de producción alóctona — sobre todo formas de sigillata gálica así como hispánica- 
Son el grueso del corpus, el $87,7 \%$ del total del conjunto. De las 107 piezas estudiadas, 73 las hemos catalogado como epigráficas, aquellas que conservan restos de letras identificadas como tales (núm. 16-88), y 34 como anepigráficas, formadas por signos, símbolos, numerales o marcas figurativas de diversa índole (núm. 89-122). Esta prevalencia de los textos de 3 a 1 nos podría estar indicando un nivel de alfabetización, básico al menos, a tener en cuenta entre los propietarios de las vajillas rescatadas. Estos personajes que salen ahora del anonimato parecen pertenecer a los sectores más humildes de la sociedad emeritense de la segunda mitad del siglo I d.C., según informan los rasgos onomásticos de los ejemplos mejor conservados.

Como ocurre en otros conjuntos cerámicos peninsulares estudiados (Segobriga, Complutum, etc.), estos grafitos se graban mayoritariamente sobre sigillatas: de los 107 grafitos postcocción que publicamos, 94 están sobre sigillatas, un $88 \%$ (núm 17-81 y 92-120); resultando anecdótica su presencia sobre vajilla de otra tipología cerámica (solo en cuatro piezas de paredes finas —núm. 16 y 89-91- y en nueve de cerámica común —núm. 82-88 y 121-122-). Este hecho evidenciaría el alto consumo que tuvo este tipo de cerámicas en todos los estratos sociales y el codiciado valor que llegaron a adquirir especialmente entre los miembros más humildes de las familiae romanas emeritenses. La circunstancia de que todas las sigillatas grafitadas, salvo una (itálica), se repartan casi al $50 \%$ entre gálicas e hispánicas estaría confirmando la data del último cuarto del siglo I d.C. como lapso temporal en que fueron desechadas estas vajillas en el vertedero/puticuli intervenido.

Las formas habituales que merecieron ser marcadas con uno o varios grafitos son las más corrientes de la vajilla de mesa personal: copas, platos y cuencos. En el primer grupo de las copas, el más representado de todo el conjunto con cuarenta y seis ejemplos, destaca la abundancia de la forma 27 tanto en las sigillatas gálicas (núm. 36-46 y 103-107) como hispánicas (núm. 57-70 y 113-114), con quince y dieciséis piezas grafitadas respectivamente. Los platos, treinta y uno en total, son mayoritariamente de las formas gálicas Drag. 15/17 (núm. 18-21 y 92-94) y 18 (núm. 22-31 y 95-96) e hispánicas 15/17 (núm. 51-56 y 109-111). Mientras que de la veintena de cuencos esgrafiados, la forma más repetida es la 37 de sigillata hispánica, con trece muestras (núm. 72-81 y 120). No obstante, también fueron susceptibles de ser grafitadas tres botellas, tres ollas y una escudilla, todas de cerámica común (núm. 82-88 y 121-122), así como dos vasos, una jarra y una lucerna de paredes finas (núm. 16 y 89-91) (Tabla 2).

El lugar predilecto de las vajillas para realizar las incisiones fue con diferencia la base, mayoritariamente por su lado exterior. Sin embargo, en las copas se nota una preferencia también considerable por grabar los grafitos en su pared al exterior. Algo que de igual modo observamos en otras formas minoritarias de la muestra, como las botellas (núm. 82, 86, 88 y 122). Sin duda, las limitaciones formales de los propios soportes condicionaban el lugar donde marcar las vajillas. $\mathrm{Pa}$ rece que como primera opción, por regla general, se buscaba la zona natural menos visible de la pieza y más cómoda para practicar el esgrafiado, su base exterior, 
y si ésta no reunía las dimensiones exigidas, como vemos en muchas de las copas, el autor del grafito se decantaba por la superficie exterior de la pared. Sin embargo no faltan excepciones a esta tendencia, con algunos grafitos incisos en el borde de dos ollas y una escudilla (núm. 83, 84 y 87), de cerámica común, o incluso otros en el fondo interior de platos (núm. 95 y 109), cuencos (núm. 74, 108 y 115) y copas (núm 112), de terra sigillata (Tabla 2).

\subsubsection{Epigráficos}

De los 73 grafitos catalogados como epigráficos, 54 se conservan completos (Tabla 1). De estos últimos estadísticamente despuntan los 39 que son monolíteros / bilíteros / trilíteros: 13 están formados por solo una letra, 17 por dos y 9 se desarrollan hasta las tres letras; a modo de iniciales o abreviaturas del nombre personal del poseedor de cada una de las vajillas. Sin duda, en no pocos casos estas iniciales enmascararían individuos con duo o tria nomina. Parece que esta fue la tendencia más corriente de marcar la propiedad, con una, dos o tres iniciales onomásticas, así como, también alternativamente, mediante la grabación completa del nominal, bien en genitivo bien en nominativo. Así, hemos llegado a documentar hasta 13 grafitos donde se evidencia esta circunstancia, prevaleciendo los que expresaron la posesión con su nombre en genitivo sobre los que lo hicieron en nominativo (Tabla 1).

La antroponimía que nos revela este estudio no se aparta de los cánones hasta ahora transmitidos por la epigrafía mayor de la antigua colonia emeritense. La mayoría de los nominales completos o restituidos son de clara raíz latina (p.ej. Iulius, Placidi, Silvani, Primigeni, Crescens, lucundi, Fortunatus, Avitus), no faltan-

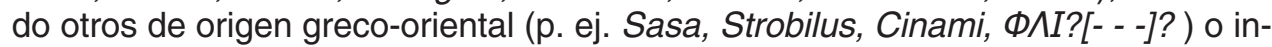
cluso indígena (Tocteai, con las debidas reservas). Casi todos ellos, cognomina o nomina unica, van asociados ineludiblemente al estamento servil, con lo que se confirmaría la máxima, ya apuntada en otros estudios similares, de que son principalmente los libertos y esclavos domésticos los que acostumbraban a reafirmar, con su nombre o con una marca, la propiedad de sus vajillas de mesa para diferenciarlas de las de sus iguales en el uso cotidiano.

La paleografía de esta escritura peculiar es la habitual que conocemos en otros conjuntos cerámicos grafitados similares: letras que tienden a los tipos capitales, a menudo con poco éxito, de formas angulosas (p. ej. núm. 25, 45, 52, 58, 59) con trazos que frecuentemente se cortan (p. ej. núm. $79,82,84$ ) y se prolongan (p. ej. núm. 23, 25, 51), nexos (núm. 21, 60, 78) y algunos tipos cursivizantes, más visibles en las $E$ (p. ej. núm. 16, 19, 36, 59) y en las $A$ (núm. 17, 21, 23, 24, 79) . Las características formales de los soportes, normalmente cóncavos, y su carácter efímero, unido a un bajo nivel de instrucción de los autores de los epígrafes, condicionarían, sin duda, esta particular forma de escritura. ${ }^{13}$

13 SÁNCHEZ-LAFUENTE PÉREZ, J., RASCÓN MARQUÉS, S. y POLO LÓPEZ, J., «Grafitos sobre instrumental doméstico en Hispania», XI Congresso Internazionale di Epigrafia Greca e Latina (Roma, 1997). Atti, (1999), p. 584. 


\section{Cerámica local de acabado irisado}

16. Lucerna en cerámica local de acabado irisado, forma Den. VA, casi completa, solo le falta parte del piquero. El barniz ha sufrido abrasión por la zona del disco. Porta dos grafitos iguales, de $0,9 \mathrm{~cm}$ de altura, uno grabado en la base y el otro en el disco. Se lee: NII. E representada con las dos barras verticales. Restitución: $\mathrm{Ne}(--$-). Estaríamos ante la abreviación de un nominal como Nepos, $\mathrm{Ne}$ reus/a, etc. ${ }^{14}$

\section{En terra sigillata itálica}

17. Consp. 24. Fragmento de la base de un cuenco de terra sigillata itálica, forma Consp. 24 con sello in planta pedis del taller de Crestus. Conserva grafito de $1,2 \mathrm{~cm}$ de altura, grabado mediante incisión profunda en la base exterior, dentro del anillo del pie. Hasta la fractura leemos: CA. Restitución posible: Ca[- - -?].

\section{En terra sigillata gálica}

18. Drag. 15/17. Fragmento de la base y del pie de un plato de terra sigillata gálica, forma Drag. 15/17, con sigillum fracturado. Porta grafito bilítero de $2 \mathrm{~cm}$ de altura en la base al exterior, dentro del anillo del pie; su incisión es poco profunda y el ductus muy irregular. Se lee: $C E$. La barra inferior de la $E$ es más prolongada. $\mathrm{Ce}(-$ - -), podría tratarse de la abreviación de un nombre personal como Celer, con varios individuos en Mérida. ${ }^{15}$

19. Drag. 15/17. Fragmento de la base de un plato de terra sigillata gálica, forma Drag. 15/17, con sigillum Cirratus. Presenta grafito bilítero de $2 \mathrm{~cm}$ de altura, en el fondo exterior dentro del anillo del pie. Leemos: FE. La grafía empleada es arcaica, con la $\mathrm{E}$ formada por dos barras verticales paralelas y la $\mathrm{F}$ igual aunque la segunda barra mucho más corta. Estaríamos ante las iniciales de un nominal como Felix, etc. ${ }^{16}$

20. Drag. 15/17. Fragmento de la base de un plato de terra sigillata gálica, forma Drag. 15/17, que conserva grafito de $0,8 \mathrm{~cm}$ de altura, grabado dentro del anillo del pie mediante incisión ancha y profunda. Hasta la fractura de la pieza se lee: LV. Posible restitución: Lu[- - -?].

21. Drag. 15/17. Fragmento de la base de un plato de terra sigillata gálica, forma Drag. 15/17, con sigillum Ferrus Fecit. Conserva un grafito de $2 \mathrm{~cm}$ de altura, grabado al exterior, dentro del anillo del pie, mediante una incisión ancha producida por la sobreescritura de los trazos originales. Hasta la fractura de la pieza se puede leer: MA. Las dos letras están nexadas. Restitución posible: Ma[- - -?].

22. Drag. 18. Fragmento correspondiente a la mitad aproximada de la base de un plato de terra sigillata gálica, forma Drag. 18, con sigillum Canrucatus, que por-

14 VV.AA. («GRUPO MÉRIDA»), Atlas antroponímico de la Lusitania romana, Mérida-Burdeos, 2003 , p.246.

15 Ídem, p.138. 
ta grafito completo de $1 \mathrm{~cm}$ de altura, grabado con firmeza en el fondo externo de la pieza, ligeramente desplazado del centro del anillo fijado por el pie. Se lee: PLACIDI. Este nominal, aquí en genitivo, está bien representado en la epigrafía emeritense con cinco individuos más portándolo como cognomen o nomen unicum. ${ }^{17}$

23. Drag. 18. Fragmento de parte de la base y del pie de un plato de terra sigillata gálica, forma Drag. 18, que conserva grafito completo, de 1,5 cm de altura, grabado en la pared exterior junto al anillo al pie, con el plato puesto boca abajo. La incisión es poco profunda y el ductus poco cuidado. Se lee: TOCTEAI. La $C$ y la $E$ prolongan sus trazos inferiores, subrayando a las letras que les siguen. Parece un nombre personal en genitivo de confusa interpretación. Se puede aventurar un radical onomástico $T o(n) c$-, autóctono de la región lusitana y muy extendido por toda ella. ${ }^{18} \mathrm{~A}$ partir de aquí, el nombre personal más aproximado es el indígena Toncetus/a, ${ }^{19}$ que al pasarlo por escrito habría sufrido una evidente alteración ortográfica debido, seguramente, al bajo nivel de alfabetización de su autor.

24. Drag. 18. Fragmento de la base y del pie de un plato de terra sigillata gálica, forma Drag. 18, con sello de taller ilegible. Conserva un grafito de 1,2 cm de altura máxima, que ha llegado fracturado. Se grabó al exterior dentro del anillo del pie. Se lee: PLAV. El grupo vocálico AV está nexado. Restitución propuesta: Plau[t- - - -?]. Por lo que podría tratarse del nominativo o genitivo del cognomen Plautus, Plautilla o Plauti(a)nus, presentes en algunas inscripciones peninsulares. ${ }^{20}$ En Mérida, más concretamente en los límites occidentales de su territorium, solo está documentado como cognomen Plautilla, en un epígrafe votivo. ${ }^{21}$ Otra posibilidad es que el nombre personal grafitado sea un gentilicio como Plautius/a, del que disponemos en la antigua capital lusitana también un solo ejemplo epigráfico, Plautia Arethusa. ${ }^{22}$

25. Drag. 18. Fragmento de parte de la base de un plato de terra sigillata gálica de las primeras producciones. Conserva parte de un grafito de una altura máxima de 1,6 cm, que se ha grabado en sentido circular, pegado al anillo del pie de la pieza, por dentro. Leemos: +LVANI. La incisión es ancha y profunda, el ductus firme y regular. Proponemos como restitución más plausible: [S]!lvani, el nombre en genitivo del propietario indicando la posesión de la pieza. Aunque también caben otras posibilidades menos frecuentes como: Silvanius/a, en nominativo, o bien Silvanilla/ae o Silvanianus/i, tanto en nominativo como genitivo. ${ }^{23}$

16 SOLIN, H. \& SALOMIES, O., Repertorium nominum gentilium et cognominum latinorum, Hildesheim-Zürich-New York, 1994, pp. 330-331.

17 HEp 15, 21 y VV.AA. («GRUPO MÉRIDA»), Atlas antroponímico..., p.264.

18 VV.AA. («GRUPO MÉRIDA»), Atlas antroponímico...., p.362.

19 Ídem, pp. 320 y 322.

20 ABASCAL PALAZÓN, J.M., Los nombres personales en las inscripciones latinas de Hispania, Murcia, 1994, p.461.

21 HEp 14, 451; Elvas, Portugal.

22 VV.AA. («GRUPO MÉRIDA»), Atlas antroponímico..., p.264.

${ }^{23}$ ABASCAL PALAZÓN, J.M., Los nombres personales..., p.512. 
26. Drag. 18. Fragmento de base de un plato de terra sigillata gálica, forma Drag. 18, que conserva incompleto un grafito en el fondo exterior, dentro del anillo del pie. Se puede leer: $++C+$. Las tres + son todas barras verticales cortadas por la fractura de la pieza, por lo que podemos suponer las primeras letras de un nominal como Licinius, Licinus o Licinianus.

27. Drag. 18. Dos fragmentos que casan de la base de un plato de terra sigillata gálica, forma Drag. 18, con sello de taller ilegible. Conserva grafito de 1,8 cm de altura en la base al exterior, en el centro del anillo que forma el pie de la pieza. Leemos: $P(--$-) $M(--$ - ). Se podría tratar de las iniciales del mismo personaje que encontramos en otro grafito ( $n^{\circ}$ 59), PMIISGII. Las formas de las letras en ambos textos son elocuentemente similares.

28. Drag. 18. Un fragmento de la base de un plato de terra sigillata gálica, forma Drag. 18, que conserva grafito de $2 \mathrm{~cm}$ de altura en la base exterior, dentro del anillo del pie, grabado mediante incisión profunda y rectilínea. Se lee hasta la fractura: SA. Restituimos: Sa[sa ?]. La identidad de estas dos letras y la similitud de sus trazos con las del grafito $\mathrm{n}^{\circ} 37$ nos lleva a pensar que es la misma mano la que ha grabado ambas marcas de propiedad. Sasa es un cognomen/nomen unicum masculino de origen iranio, sólo documentado en una veintena de inscripciones de esclavos y libertos descubiertas en Italia y el norte de África. ${ }^{24}$

29. Drag. 18. Fragmento correspondiente a la base de un plato de terra sigillata gálica, forma Drag. 18, con sigillum de Nicio. Tiene grafito de 2,3 cm de altura en la base exterior, dentro del anillo del pie. Parece una $\mathrm{N}$ inversa, aunque también se podría interpretar como una secuencia bilítera nexada: $V A(-$ - -).

30. Drag. 18. Fragmento de la base de un plato de terra sigillata gálica, forma Drag. 18, que conserva fracturado un grafito de $1,8 \mathrm{~cm}$ de altura, grabado en el fondo al exterior mediante una incisión ancha y profunda. Solo leemos dos letras: $C+$. Restituimos: $C+[---$ ?] . La + es una línea recta vertical que bien podría ser una I, L o una de las dos astas de una E cursiva.

31. Drag. 18. Fragmento de base de un plato de terra sigillata gálica, forma Drag. 18, con sello de taller roto, que conserva grafito de $1,1 \mathrm{~cm}$ de altura, en el fondo al exterior, dentro del anillo del pie. Se ha trazado con ductus irregular. Solo se lee una letra debido a la fractura de la pieza: $P$. Restitución propuesta: [- -]?P(- - -).

32. Drag. 24-25. Fragmento de base de una copa de terra sigillata gálica, forma Drag. 24-25, con sigillum de Rufinus, que conserva un grafito de $1,1 \mathrm{~cm}$ de altura en la base exterior, dentro del anillo del pie, grabado en sentido circular. Leemos: $A M$. La fractura de la pieza impide saber si el grafito se compondría de una letra más detrás de la $M$. Por tanto, restituimos: $A m[-]$ ?(- - -).

33. Drag. 24-25. Copa de terra sigillata gálica, forma Drag. 24-25, con sello de taller ilegible, que conserva grafito bilítero de $1,5 \mathrm{~cm}$ de altura en la parte baja del

${ }^{24}$ SOLIN, H., Die Stadtrömischen sklavennamen. Ein namenbuch, Stuttgart, 1996, p.606. 
cuerpo exterior, junto al anillo del pie. Se lee: $C L$. Podrían ser la iniciales de un duo nomina, C(- - ) L(- - ), o, mejor, la abreviación de un nombre personal, Cl(- - -). Esta misma secuencia bilítera se grabó en la pieza no 76 .

34. Drag. 18. Fragmento de base de una copa de terra sigillata gálica con sigiIlum roto, que conserva grafito de $1,2 \mathrm{~cm}$ de altura en la base exterior, dentro del anillo del pie. Proponemos la siguiente lectura: PM[- - -]?. La fractura de la pieza impide saber si el grafito continuaba. La P no se habría trazado con demasiado acierto, situando su seno en medio del asta vertical. La M tiene rasgos librarios. Esta secuencia inicial $P M$ - se repite en otros dos grafitos del conjunto ( $n-27$ y 59), con los que podría compartir propietario, aunque el tipo de letra no sea coincidente. Otra interpretación es que fuera un grafito en signario griego: Ф^I[- - -]?. Así, podría ser el

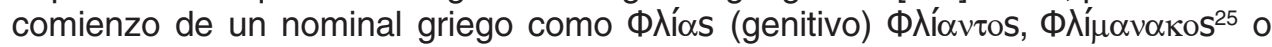
Ф人ióvos.

35. Drag. 24-25. Fragmento correspondiente a la base de una copa de terra sigillata gálica, forma Drag. 24-25, con sigillum ilegible, que porta grafito monolítero de $1 \mathrm{~cm}$ de altura en la base exterior junto al anillo del pie. Lectura: $M(---)$. A buen seguro es la inicial del nombre personal del propietario, que se repite en otras piezas de este conjunto ( $\mathrm{n}^{\circ}$ 39, 40, 54 y 87.).

36. Drag. 27. Fragmento de la base de una copa de terra sigillata gálica, forma Drag. 27, con sello del taller de Albus. Porta grafito de $0,5 \mathrm{~cm}$ de altura máxima en el fondo exterior dentro del anillo del pie, grabado en sentido circular mediante incisión profunda y ductus poco regular por lo constreñido del campo epigráfico elegido. Se lee: PRIMIGIINI. La E se ha representado con la doble barra vertical. Estamos sin duda ante el nombre en genitivo del propietario del vaso, Primigenius, bien representado en la epigrafía emeritense. ${ }^{26}$

37. Drag. 27 ó 24-25. Un fragmento de la base de una copa de terra sigillata gálica, forma Drag. 27 ó 24/25, con sello del taller de Masculus. Conserva grafito completo de 1,3 cm de altura máxima, grabado en la base exterior dentro del anillo del pie, pegado a él, en sentido circular y ductus irregular. Se lee: SASA. Este nombre personal, un cognomen masculino, que aquí aparece en nominativo, también se habría marcado sobre otra pieza de la vajilla personal de su propietario, un plato de terra sigillata gálica ( $n$ - 28). Se trataría del primer testimonio de este antropónimo, de raíz irania, documentado en la Península Ibérica.

38. Drag. 27. Fragmento correspondiente a la base de una copa de terra sigillata gálica, forma Drag. 27, en el que se ha inciso un grafito de 1/1,8 cm de altura. Se localiza en la base al exterior, dentro del anillo formado por el pie de la pieza. Parece que se han querido trazar dos letras: una $M$, inclinada, seguida de una I, muy prolongada hacia abajo. Con ciertas reservas, pues, proponemos esta lectura: MI. Que podríamos interpretar como un nombre personal abreviado, Mi(- - -).

${ }_{25}$ IosPe I2. 106, Olbia. Agradecemos a la profesora Mํㅡ Paz De Hoz García-Bellido la noticia de estos paralelos onomásticos griegos.

${ }^{26}$ VV.AA. («GRUPO MÉRIDA»), Atlas antroponímico...., p.269. 
Otra interpretación factible es considerar esta secuencia bilítera como el pronombre personal de primera persona singular en dativo, mihi, con una lógica contracción vocálica. De esta manera el poseedor de la pieza querría expresar con énfasis este objeto como suyo («Es mío», diríamos hoy). La pieza n 62 porta las mismas letras grafitadas, aunque su lectura resulta más clara.

39. Drag. 27. Fragmento de base y cuerpo de una copa de terra sigillata gálica, forma Drag. 27, con sigillum de Dodo y con grafito monolítero de 1,5 cm de altura, grabado en el fondo exterior, dentro del anillo del pie. Se lee: $M(--$-). Idéntico grafito también en otras piezas de este conjunto: ํo 35, 40, 54 y 87.

40. Drag. 27. Un fragmento del cuerpo de una copa de terra sigillata gálica, forma Drag. 27 carenada, que conserva grafito monolítero de $0,8 \mathrm{~cm}$ de altura en la pared exterior. Se lee: $M$. Además, un corto trazo vertical inclinado aparece inciso debajo del primer ángulo de la letra, lo que supone interpretarlo quizás como la barra desplazada de una $A$ cursiva. Entonces leeríamos una secuencia bilítera nexada: $A M$. Posibles restituciones: $M(--)$ o $A m(---)$. Hay otras piezas marcadas con una $M$ en este conjunto: $n=35,39,54$ y 87.

41. Drag. 27. Un fragmento correspondiente a la base de una copa de terra sigillata gálica, forma Drag. 27, con sigillum de Niels?. Conserva completo un grafito bilítero de 0,6 cm de altura, grabado en la base al exterior dentro del anillo del pie. Leemos: NI. Restitución posible: Ni(- - -). Apostamos por la abreviatura de un cognomen como Niger o Nigra, bien representado en las inscripciones locales y provinciales. ${ }^{27}$ Encontramos otro grafito con las mismas letras en este mismo conjunto (cf. $\mathrm{n}^{\circ}$ 63).

42. Drag. 27. Un fragmento correspondiente a la base de una copa de terra sigillata gálica, forma Drag. 27, con sigillum de Senecio. Porta grafito monolítero de $0,8 \mathrm{~cm}$ de altura en la base al exterior dentro del anillo del pie: $R(--$-). En la misma zona de la pieza aparecen otros grafitos de incisión más superficial y de dudosa interpretación.

43. Drag. 27. Un fragmento que corresponde a parte de la base y el cuerpo de una copa de terra sigillata gálica, forma Drag. 27, con sigillum ilegible. Conserva restos de grafito en la base exterior dentro del anillo del pie. Su altura máxima es de $1,1 \mathrm{~cm}$ y está trazado en sentido circular. Se puede leer: [- - -]?NF+. La F tiene las astas horizontales formando un ángulo (<).

44. Drag. 27. Un fragmento de la base de una copa de terra sigillata gálica, forma Drag. 27, con sigillum roto ilegible, que conserva grafito de $1,1 \mathrm{~cm}$ de altura en la base exterior dentro del anillo del pie. Se puede leer: [-]?F(- - -).

45. Drag. 27. Fragmento correspondiente al perfil completo de una copa de terra sigillata gálica, forma Drag. 27 , de $3,5 \mathrm{~cm}$ de altura, que conserva grafito incompleto, de $1 \mathrm{~cm}$ de altura, en el cuerpo al exterior. Se ha grabado con firmeza en

\footnotetext{
27 Ídem, p.247.
} 
sentido horizontal colocando la pieza boca abajo. Se lee: [- - -]BAE. Y podemos restituir v.g.: un cognomen femenino en genitivo como [Pro]bae ${ }^{28} \mathrm{o}$ uno masculino como [Gal]bae. ${ }^{29}$

46. Drag. 27 ó $24 / 25$. Un fragmento de la base de una copa de terra sigillata gálica, forma Drag. 27 ó 24/25, con sigillum de Verigius?. Conserva el final de un grafito de $0,8 \mathrm{~cm}$ de altura en la base al exterior, dentro del anillo del pie, grabado mediante ancha incisión en sentido circular. Se lee: RTIS. Restitución: [- - - rrtis. Parece el final de un nombre personal en genitivo como, por ejemplo, Sollers. ${ }^{30}$

47. Drag. 29. Fragmento de la base y del cuerpo de un cuenco de terra sigillata gálica del taller de Montans, forma Drag. 29, que conserva parte de un grafito en la base al exterior, junto al anillo del pie. Tiene una altura de $0,8 \mathrm{~cm}$ y se ha grabado mediante una incisión firme, pese a que el ductus es algo irregular. Leemos: SALV. Restituciones propuestas: Salv[ianus/i - - -?] o Salu[taris - - ?], o bien Salv[ius/a - - -?], cognomina los dos primeros presentes en la antigua Emerita y el último, solo como gentilicio, también con varias ocurrencias en la colonia. ${ }^{31} \mathrm{Sin}$ embargo, no podemos obviar otras opciones onomásticas con este mismo comienzo. ${ }^{32}$

48. Drag. 33. Fragmento de cuerpo de una copa de terra sigillata gálica, forma Drag. 33, que conserva grafito de $1 \mathrm{~cm}$ de altura en la pared exterior. En el caso de tratarse de un grafito epigráfico la lectura propuesta sería: [- - -]?AL[- - -]? Las dos letras irían nexadas, la $A$ sin travesaño y el asta horizontal de la $L$ arranca de algo más arriba. No obstante, tampoco se puede descartar una marca o signo personal.

49. Drag. 37. Un fragmento de la base y del cuerpo de un cuenco de terra sigillata gálica, forma Drag. 37 , que porta un grafito bilítero de $1,2 \mathrm{~cm}$ de altura, grabado en la base exterior, dentro del anillo del pie, mediante incisión profunda y ductus firme y elegante (los pies de las letras aparecen bien marcados). Se lee: FE(- -). Posiblemente sea la abreviatura de un nombre personal como Felix o Festus, muy abundantes en la colonia. ${ }^{33}$

50. Drag. 37. Fragmento correspondiente a la base de un cuenco de terra sigillata gálica, forma Drag. 37, con sigillum de Martialis, que porta grafito monolítero en el fondo exterior, dentro del anillo del pie. Parece tratarse de una $E$ de $2,3 \mathrm{~cm}$ de altura con el trazo horizontal inferior prolongado y curvado hacia dentro.

\section{En terra sigillata hispánica}

51. Hisp. 15/17. Dos fragmentos que pegan de la mitad de la base y una pequeña parte del perfil completo de un plato de terra sigillata hispánica, forma 15/17. Conserva completo un grafito en la base al exterior, junto al anillo del pie y en paralelo a él, grabado con la pieza apoyada boca abajo. La altura de las letras

28 CIL II, 573; Mérida.

29 VV.AA. («GRUPO MÉRIDA»), Atlas antroponímico...., p.183.

${ }^{30}$ ABASCAL PALAZÓN, J.M., Los nombres personales..., p.514 y KAJANTO, I., The Latin cognomina, Roma, 1965, p.250.

31 VV.AA. («GRUPO MÉRIDA»), Atlas antroponímico...., p.292.

32 SOLIN, H. \& SALOMIES, O., Repertorium nominum..., p.396.

33 VV.AA. («GRUPO MÉRIDA»), Atlas antroponímico...., p.171. 
fluctúa entre los 0,9 cm de la primera y los 1,3 cm de la última. La incisión se ha marcado con firmeza. Se lee: CRESC.F. La R prolonga la cola hacia abajo y la $\mathrm{E}$ su trazo horizontal inferior hasta dos letras más, superponiéndose a ellas. La interpunción es un punto. Restitución propuesta: Cresc(ens)·f(ecit). El nombre del propietario del plato es muy conocido en Mérida. ${ }^{34}$ Tenemos infra otra pieza que pudo pertenecer al mismo propietario (cf. $\mathrm{n}^{\circ} \mathbf{7 7}$ ).

52. Hisp. 15/17. Un fragmento correspondiente a la base completa de un plato de terra sigillata hispánica, forma 15/17, con sello ilegible. Conserva un grafito completo de un 0,5 cm de altura, grabado en la base al exterior dentro del anillo del pie, en medio de un desconchón que alteró la superficie original del acabado de la pieza. La incisión es fina y superficial. Se puede leer: DOMNI. Restituimos: dom(i)ni. Se trataría de un genitivo sincopado de dominus, con el sentido de «es del dueño (de la casa)» o, tal vez mejor, «esta pieza tiene dueño», con un regusto irónico; como ha apuntado V.H. Correia para un grafito cerámico muy similar descubierto en Conimbriga. ${ }^{35}$ Sin embargo, encontramos un paralelo muy próximo en el yacimiento de «El Castillo» (Solana de los Barros, Badajoz), donde se halló un cuenco de terra sigillata hispánica, forma 37 , en el que aparece grafitado DOMNICA. ${ }^{36}$

53. Hisp. 15/17. Tres fragmentos que casan de la base de un plato de terra sigillata hispánica, forma 15/17. Porta grafito monolítero de 1,1 cm de altura, grabado mediante profunda incisión en el exterior de la base, dentro del anillo del pie, en el centro del mismo. Leemos: E(- - -). También en la misma localización se grafitaron con una incisión más superficial, en un momento anterior, tres líneas rectas (dos de ellas paralelas) de 3,5 cm de longitud máxima y de interpretación incierta; aunque proponemos con ciertas reservas la siguiente lectura: VI (¿iniciales onomásticas o numeral?). Por tanto, la pieza o bien pasó por dos manos que quisieron ambas dejar patente su marca de pertenencia, o bien fue el mismo autor el que grabó primero un numeral y posteriormente quiso escribir la inicial de su nombre para reforzar la identificación del plato como parte de su vajilla personal.

54. Hisp. 15/17. Fragmento de la base de un plato de terra sigillata hispánica, forma 15/17, con sigillum de Paternus, que conserva grafito de $0,6 \mathrm{~cm}$ de altura en la base exterior dentro del anillo del pie. Aparentemente, por el vacat que existe entre la única letra conservada y la rotura que ha sufrido la pieza, parece un grafito monolítero: $M(--$ - ). Hay otros recipientes de este conjunto marcados también sólo con una $M: n^{\circ}$ 35, 39, 40 y 87 .

55. Hisp. 15/17. Fragmento de parte de la base de un plato de terra sigillata hispánica, forma 15/17, que conserva grafito de $0,9 \mathrm{~cm}$ de altura en la base exte-

34 Ídem., p.155. También se grafitó CRESCENTES sobre el disco de una lucerna emeritense Den. VA, muy probablemente coetánea a nuestro plato (cf. RODRÍGUEZ MARTÍN, F.G., Las lucernas romanas..., pp.181-182 y fig.XXV,72). 212.

${ }^{35}$ CORREIA, V.H., «Um grafito de propriedade, de Conimbriga», Ficheiro Epigráfico, 47, (1994), p.

${ }^{36}$ RODRÍGUEZ MARTÍN, F.G. y JEREZ LINDE, J.M., «Notas para la clasificación de los grafitos, sobre cerámica romana, procedentes de la cuenca media del Guadiana», Boletín de la Asociación Española de Amigos de la Arqueología, 35, (1995), p.275 y lám. XIII. 
rior dentro del anillo del pie, grabado en círculo. La fractura de la pieza solo permite conocer su final: + CICII. Restituciones posibles: Acicii ?, con un paralelo onomástico en Cádiz de lectura discutible en forma de gentilicio femenino; ${ }^{3}$ y [F] cicii ?, con un paralelo dudoso en el mismo conventus emeritense (Talavera de la Reina, Toledo) en un bloque marmóreo con epígrafe funerario, donde se lee FIICICII, tal vez el cognomen del difunto en genitivo. ${ }^{38}$

56. Hisp. 15/17. Un fragmento amorfo de la base de un plato de terra sigillata hispánica, forma 15/17, que conserva grafito de 1,2 cm de altura máxima, bien en el interior o exterior del fondo de la pieza (difícil de precisar por lo exiguo conservado). Se puede leer: IA[- - -?] vel [- - -?]VI, dependiendo de la perspectiva. Así pues, podría interpretarse en el primer caso como las iniciales onomásticas del propietario o, también, como un indicativo numeral en la segunda propuesta.

57. Hisp. 27. Fragmento que corresponde a la base de una copa de terra sigillata hispánica del taller de Andújar, forma 27, con sigillum de Tittius Oppius. Porta grafito completo de $0,8 \mathrm{~cm}$ de altura en la base exterior, dentro del anillo del pie, grabado en círculo: IVCVNDI. Nombre personal en genitivo, indicador del propietario de la pieza, lucundus, un cognomen muy repetido en Mérida entre el colectivo libertino. ${ }^{39}$ Curiosamente el mismo nominal se repite en dos grafitos sobre sendas piezas de terra sigillata hispánica halladas en Mérida. ${ }^{40}$

58. Hisp. 27. Fragmento de la base de una copa de terra sigillata hispánica, forma 27, con sigillum de Cantaber. Conserva grafito de $2 \mathrm{~cm}$ de altura máxima, elaborado mediante incisiones anchas y remarcadas, en la base al exterior dentro del anillo del pie. Con claridad se lee: SAT. Restituimos como opciones onomásticas más plausibles: Sat(urninus/a), en nominativo, o Sat(urnini/ae), en genitivo.

59. Hisp. 27. Fragmento de una parte del cuerpo de una copa de terra sigillata hispánica, forma 27, del taller de Andújar. Conserva grafito de 1,5 cm de altura máxima grabado con incisión ancha y ductus firme en la pared exterior. Se puede leer: PMIISGII. Podemos restiuir: P(ublius/ii) Mesge[nius/ii - - -?]. Las E son dos astas verticales paralelas y la consonante $C$ se ha escrito como $G$, tal vez debido a causas fonéticas (por la sonorización de la oclusiva), o tal vez debido a la vacilación del autor a causa de su bajo nivel de instrucción. Estaríamos, lo más probable, ante un tria nomina donde el rastro del cognomen se ha perdido debido a la fragmentariedad de lo conservado. El gentilicio Mescenius/a es un unicum en la Península, procediendo la mayor parte de los individuos documentados de la provincia balcánica de Dalmacia. ${ }^{41}$

37 Se trata del epitafio de la centenaria Acicia Antuca (AE 1920, 79). O, según HEpOL 6200, Acilia Antuca. También encontramos en genitivo masculino, Acici, en un sello anfórico hallado en Como, Italia (PAIS, E., Corporis inscriptionum Latinarum supplementa Italica, Roma, 1884, № 1077, 19).

${ }^{38}$ CIL II 939 = HEpOL 449.

39 VV.AA. («GRUPO MÉRIDA»), Atlas antroponímico...., p.196.

40 Se trata de un plato y una copa, Hisp. 27 (cf. MAYET, F., Les céramiques sigillées hispaniques: Contribution à l'histoire économique de la Péninsule Ibérique sous l'Empire Romain, Paris, 1984, p.98, no 100 y 101, planche CXXVII).

${ }^{41}$ Cf. SOLIN, H. \& SALOMIES, O., Repertorium nominum..., p.117 y ALFÖLDY, G., Die Personennamen in der römischen Provinz Dalmatia, Heidelberg, 1969, pp. 157, 260, 303 y 314. 
60. Hisp. 27 ó 24/25. Un fragmento correspondiente a la base y a parte del cuerpo de una copa de terra sigillata hispánica, forma 27 ó 24/25, que porta grafito completo de $1 \mathrm{~cm}$ de altura. Está grabado mediante incisión ancha y ductus firme en la zona inferior del cuerpo al exterior, con la pieza puesta boca abajo. Leemos: TAN o $T A V$. Las dos letras últimas en nexo. Podría tratarse de la abreviación de cognomina como Tanginus/a (o alguna de sus variantes radicales y sufijales) o como Taurus. ${ }^{42}$

61. Hisp. 27. Fragmento de la base de una copa de terra sigillata hispánica, forma 27 , que conserva grafito de $1,5 \mathrm{~cm}$ de altura en la base exterior, dentro del anillo del pie, grabado en sentido circular. Se lee: $Q T A$, o, tal vez, PTA. Restituimos: $Q(-$ - -) o $P(-$ - -) Ta[-?](- - -). Quizá estemos ante las iniciales de un tria nomina, pero la pérdida de una o dos letras impide una restitución fiable.

62. Hisp. 27. Fragmento de la base de una copa de terra sigillata hispánica, forma 27 , con grafito bilítero de $0,8 \mathrm{~cm}$ de altura. Está grabado mediante incisión profunda y ductus poco firme en el fondo exterior de la pieza, dentro del anillo del pie, en el mismo centro del mismo. Se lee: MI. Como en la pieza no 38 , podría ser el nombre personal abreviado del propietario, Mi(- - -); o el pronombre personal de primera persona singular en dativo, mihi, escrito como se pronunciaba, con contracción vocálica. De esta última manera el poseedor de la pieza identificaría este objeto como suyo: «Es mío», traduciríamos.

63. Hisp. 27. Fragmento de la base y del cuerpo, hasta la carena, de una copa de terra sigillata hispánica, forma 27. Conserva grafito bilítero, desconocemos si completo, al exterior en la parte baja del cuerpo junto al anillo del pie. Las letras tienen una altura de $1,5 \mathrm{~cm}$ y se han grabado mediante incisión profunda. Dos lecturas posibles, dependiendo de la perspectiva, con la pieza boca arriba o boca abajo: NI o IN. La opción que creemos más factible sería el comienzo de un nombre personal, como $\mathrm{Ni}(g e r)$. A $2,5 \mathrm{~cm}$ de la $N$, en la misma línea de escritura aparecen incisos dos trazos cruzados que interpretamos como marca distintiva de propiedad reforzando la exclusividad de la pieza. Hay otro grafito con las mismas letras en otra pieza de este mismo conjunto (cf. $n \div 0$ 41).

64. Hisp. 27. Fragmento del perfil completo de una copa de terra sigillata hispánica, forma 27 , de $4 \mathrm{~cm}$ de altura. Conserva fracturado un grafito en el cuerpo al exterior, junto al anillo del pie, que mide $1 \mathrm{~cm}$ de altura. Grabado con fina incisión y ductus firme. Se lee: MII. Varias restituciones son posibles: [- - -]mii, como el genitivo de un nombre personal masculino finalizado en -mius; ${ }^{43}$ [- - - ]me, con E formada por dos astas verticales, como el final de un nombre femenino de raíz griega en nominativo, o bien de uno también femenino en genitivo con contracción vocálica -(a)e; y Me(- - -), como la abreviación de un antropónimo imprecisable.

65. Hisp. 27. Fragmento de base de una copa de terra sigillata hispánica, forma 27, que conserva grafito monolítero de $1 \mathrm{~cm}$ de altura, en el fondo exterior, dentro del anillo del pie: $C(--)$.

42 VV.AA. («GRUPO MÉRIDA»), Atlas antroponímico...., pp. 313-317. 
66. Hisp. 27. Fragmento de base y arranque del cuerpo de una copa de terra sigillata hispánica, forma 27 , con grafito monolítero de $2 \mathrm{~cm}$ de altura, en el centro del fondo exterior, dentro del anillo del pie: $S(--)$.

67. Hisp. 27. Fragmento de parte de la base de una copa de terra sigillata hispánica, forma 27 , que conserva incompleto un grafito de $0,8 \mathrm{~cm}$ de altura en la base exterior dentro del anillo del pie, grabado en círculo. Leemos: [- - -]?+SVMI [- -]? Por lo fragmentario de lo conservado resulta arriesgado proponer una restitución del texto, sin embargo apostamos por un nominal (quizás en genitivo) como Maxsumi, por su frecuencia.

68. Hisp. 27. Fragmento de cuerpo de una copa de terra sigillata hispánica, forma 27, que conserva parte de dos grafitos grabados uno en la pared exterior y otro en la interior. El primero de $1,4 \mathrm{~cm}$ de altura tiene forma de $\mathrm{A}$ y del segundo solo se conserva apenas dos incisiones rectas, una de ellas partida.

69. Hisp. 27. Fragmento de base y del cuerpo de una copa de terra sigillata hispánica, forma 27, que conserva parte de un grafito en la pared exterior. Solo se lee con claridad una $\mathrm{A}:++A+++[---]$ ?. Todas las + son trazos verticales rectos. La + que sigue a la A podría ser parte de una $\mathrm{N}$ nexada.

70. Hisp. 27. Fragmento de la base de una copa de terra sigillata hispánica, forma 27 , con sigillum roto de taller indeterminado, que conserva parte de un grafito de $1,5 \mathrm{~cm}$ de altura máxima, en el fondo exterior, dentro del anillo del pie. Parece que se ha pretendido grabar una $\mathrm{M}$, pero lo fragmentario de lo conservado y la sobreescritura de rayas más gruesas sobre las primeras más finas impiden proponer una lectura fiable.

71. Hisp. 33 ó 46. Fragmento del cuerpo de una copa de terra sigillata hispánica, forma 33 ó 46, que conserva parte de un grafito de $1,5 \mathrm{~cm}$ de altura, en la pared exterior. Leemos: $+D I+$. La primera + parece el ángulo inferior de una $\mathrm{N}$ y la segunda + el arranque inferior de un trazo oblicuo como el de una $\mathrm{N}$ o A. Por tanto, la restitución posible podría ser: [Secu]ṇdin [- - -]? o [Secu]ṇdin [- - -]? Así, barajaríamos nominales como Secundi(a)nus/a, Secundinius/a o Secundinianus. ${ }^{44}$

72. Hisp. 35. Fragmento de borde y cuerpo de una copa de terra sigillata hispánica, forma 35, que conserva fracturado un grafito bilítero en la pared interna, junto al borde y en paralelo a él. La altura conservada de las letras es de $1 \mathrm{~cm}$ y su incisión es profunda y ancha. También se aprecian trazos de otro grafito ilegible en el exterior del cuerpo. El grafito bilítero se lee así: HI. Su restitución, considerando un nombre personal como marca de propiedad, es insegura: Hi(- - -) ० H(- - - I(- - -).

73. Hisp. 37. Dos fragmentos que casan de la base de un cuenco de terra sigillata hispánica, forma 37 , que conserva un grafito completo de $1 \mathrm{~cm}$ de altura máxima en la base al exterior, dentro del anillo del pie, trazado en sentido circular. Se lee: VKDEDORI. Su interpretación es una incógnita.

\footnotetext{
43 SOLIN, H. \& SALOMIES, O., Repertorium nominum..., pp. 243-4 y 448.

44 Ídem, p.399.
} 
74. Hisp. 37. Fragmento correspondiente a la base de un cuenco de terra sigillata hispánica, forma 37 con metopas, que conserva un grafito trilítero de $1 \mathrm{~cm}$ de altura en el fondo interior de la pieza. Se lee: DOM. Se ha grabado con firmeza y el ductus es regular. Seguramente se trate de la abreviación del nombre del propietario: Dom(itius/a) o Dom(esticus/a) o cualquier otro menos corriente. ${ }^{45}$ Aunque no podemos descartar que sean las primeras letras de domini, en alusión al dueño de la casa como propietario inicial de la pieza (cf. nํ52).

75. Hisp. 37. Dos fragmentos que casan pertenecientes a una parte del cuerpo de un cuenco de terra sigillata hispánica, forma 37 (decoración metopada). Conserva grafito en la pared interna, desconocemos si completo, que mide $2 \mathrm{~cm}$ de altura y que se ha grabado con incisiones superficiales y poco firmes. Proponemos las siguientes lecturas posibles: LIC[- - -]?, identificándose con un cognomen como Licinianus/a ${ }^{46}$ o un gentilicio como Licinius/a; ${ }^{47}$ o tal vez IIC[- - -]? o IIG[- - -]?, que podrían ser las iniciales de nombres como Echion o Egnatius, o por qué no de otros como $(H)$ ector o $(H)$ egemon, presentes en la epigrafía emeritense. ${ }^{48}$

76. Hisp. 37. Fragmento de la base y de la parte inferior del cuerpo de un cuenco de terra sigillata hispánica, forma 37 con metopas, que conserva un grafito bilítero de $1 \mathrm{~cm}$ de altura, grabado en la base al exterior, dentro del anillo del pie, muy pegado al borde. La incisión es ancha y el ductus firme. Se lee: CL. Las restituciones posibles son abundantes: como nominal abreviado, $\mathrm{Cl}(---)$, o como iniciales de un duo nomina, C(- - -) L(- - -). Otra opción, aunque menos probable, es considerarlo como cifra numérica. La misma secuencia bilítera aparece en otra pieza de este conjunto ( $n^{\circ}$ 33).

77. Hisp. 37. Fragmento correspondiente a la mitad de la base de un cuenco de terra sigillata hispánica, forma 37 con metopas, que conserva parte de un grafito en la pared exterior, junto al pie de la pieza. Las letras tienen $2 \mathrm{~cm}$ de altura y se han inciso poniendo boca abajo la vasija. Se lee: $C R+[---$ ?]. Con estas dos primeras letras el nombre personal que más se repite en Mérida es Cresce $(n) s$, aunque existen otras posibilidades igual de válidas. ${ }^{49}$ Pudiera tratarse del mismo personaje que inscribió su nombre en la pieza no 51 .

78. Hisp. 37. Fragmento perteneciente a la base y al arranque del cuerpo de un cuenco de terra sigillata hispánica, forma 37 (decoración metopada). Conserva grafito bilítero en nexo, de 1,8 cm de altura, trazado con firmeza en el fondo externo, dentro del anillo que forma el pie: $\operatorname{HE}(---)$. Podría ser la abreviación de un nombre personal como Helenus/a, Helpis, Hermes, etc. ${ }^{50}$

45 Vid. un mismo paralelo epigráfico sobre sigillata en UNZU URMENETA, M. y OZCÁRIZ GIL, P., «Grafitos nominales de la plaza del Castillo de Pamplona», Instrumenta, 32, (2009), pp. 499-512, no 9 (Fig. 9).

46 ABASCAL PALAZÓN, J.M., Los nombres personales..., p.400.

47 VV.AA. («GRUPO MÉRIDA»), Atlas antroponímico...., pp. 212-213.

48 Ídem, pp. 165 y 190, y SOLIN, H, Die Griechischen personennamen in Rom. Ein namenbuch, Berlin-New York, 2003, pp. 1655 y 1669.

49 VV.AA. («GRUPOMÉRIDA»), Atlas antroponímico, pp. 155-156.

50 Ídem, pp. 189-192; Abascal, pp. 383-386; SOLIN, H, Die Griechischen ..., pp. 1669-1672. 
79. Hisp. 37. Un fragmento de la base y del cuerpo de un cuenco de terra sigillata hispánica, forma 37 con decoración metopada, que conserva parte de un grafito en la pared exterior junto al anillo del pie, el cual sirve de línea-guía para su grabado. El campo epigráfico es la franja lisa de $2,8 \mathrm{~cm}$ de altura que hay entre el pie y la decoración a molde impresa en la pieza. A continuación del epígrafe aparece también grafitada una palma o espiga con la misma altura que el campo epigráfico. Las incisiones son anchas y profundas y se han ejecutado con un ductus firme. Leemos: [- - -?]+MA (palma) +[- - -?]. La primera + es un asta oblicua a la que se une por abajo otra vertical, la cual está cruzada por un corto trazo horizontal recto. La segunda + es el arranque superior de un asta oblicua, como la de una V.

80. Hisp. 37. Fragmento de pared de un cuenco de terra sigillata hispánica, forma 37, con decoración de cenefas enjoyadas, que conserva parte de un grafito de 1,3 cm de altura en la cara exterior de la pieza. Leemos: [- - - ? +A.

81. Hisp. 15/17. Fragmento de base de un plato de terra sigillata hispánica, forma 15/17, que conserva restos de grafito en el fondo exterior, dentro del anillo del pie. La fractura sufrida impide conocer si se trata de un texto o de diferentes marcas anepígrafas, decantándonos más por lo primero.

\section{En cerámicas comunes}

82. Botella (?). Fragmento correspondiente a la base completa de una forma cerrada (tal vez una botella) de cerámica común con engobe exterior y restos de pintura. Presenta grafito de $1 \mathrm{~cm}$ de altura en la zona baja del cuerpo al exterior, junto al pie y siguiendo el mismo sentido circular trazado por él. Se lee: $++T V-$ NATVS. Restituimos: [F]ortunatus. La incisión es muy superficial, de trazos anchos hasta la segunda $T$ y muy finos los del final, VS. Conocemos en Mérida por la epigrafía otros tres individuos más con el mismo nominal. ${ }^{51}$

83. Olla. Dos fragmentos que casan del borde de una olla de cerámica común, que porta grafito de $2 \mathrm{~cm}$ de altura sobre la parte superior del mismo borde, que es un labio exvasado almendrado. Se lee: AVITV; $A V$ - se grabaron nexadas. Restituimos: Avitu[s - - -?]. Es el cognomen hispanorromano más representado en la provincia lusitana y el tercero en toda la Península. ${ }^{52}$

84. Escudilla. Dos fragmentos que casan de parte del borde de escudilla carenada en cerámica común local. Presenta grafito de 1,2 cm de alto, inciso en el borde exterior, entre el labio y la carena: CINAMI[- - -?]. Así, tendríamos tres posibles restituciones: $\operatorname{Cin}(n) a m i$, genitivo del nombre masculino Cinnamus, ${ }^{53}$ suponiendo que el grafito no continuara por la parte perdida de la pieza; Cin(n)ami[o/-onis - - ?], forma en nominativo o genitivo masculino derivada de la anterior, ${ }^{54}$ restituyendo

\footnotetext{
51 VV.AA. («GRUPO MÉRIDA»), Atlas antroponímico..., p.178.

Ídem, p.410.

SOLIN, H., Die Stadtrömischen sklavennamen..., p.160.

4 Ídem, p.161, y KAJANTO, I., The Latin cognomina ..., p.121.
} 
una posible pérdida del texto; o $\operatorname{Cin}(n)$ ami[s/-idis - - -?], un nominativo o genitivo del nombre femenino. ${ }^{55}$

Cinnamus es préstamo onomástico del griego frecuente entre el estamento servil, ${ }^{56}$ aunque poco usado en la Península: v.g. encontramos un Cinnamus en Sagunto (CIL II2/14,1, 337) y su variante femenina Cinnamis en Lisboa (CIL II 216) o Écija (HEp 4, 682). Esclavos o libertos en todos los casos.

85. Olla biansada. Borde de Púcaro $1 f$ Smit-Nolen, de cerámica común engobada al exterior. Conserva grafito fracturado de $1,4 \mathrm{~cm}$ de altura, grabado mediante incisión ancha y profunda en la zona alta del cuerpo al exterior, en paralelo al borde. Leemos: ERO. Restituimos: Ero[- - -], muy probablemente como el comienzo del nombre personal del propietario de la pieza. Un antropónimo en cualquier caso de origen griego: Eros, Erotio(n), Erotica/us, etc. ${ }^{57}$

86. Fragmento correspondiente a la base de un recipiente tal vez cerrado de cerámica común, de pasta gruesa y cocción oxidante, con pie recto (de galleta), en el que se ha grabado un grafito, de $1,8 \mathrm{~cm}$ de altura máxima, en la parte inferior del cuerpo al exterior, muy cerca y en paralelo a la circunferencia trazada por la forma del pie. La incisión es ancha y se ha efectuado colocando la pieza boca abajo. El epígrafe no se conserva completo. Se lee: $+O B I L V+$. Podemos restituirlo así: [St]robilus [- - -]?. Este antropónimo griego ${ }^{58}$ solo estaba documentado en Hispania hasta hoy en una estela funeraria de un esclavo del siglo I d.C. ${ }^{59}$

87. Olla. Fragmento de borde de una olla de cerámica común, con grafito de $1,7 \mathrm{~cm}$ de altura, grabado en el labio: $M[---]$ ?. Otras piezas de este conjunto con $M-: n^{\circ} 35,39,40$ y 54 .

88. Botella. Fragmento del cuerpo de una botella de cerámica pintada de tradición indígena, forma Abascal $18 \mathrm{~b}$, que conserva parte de un grafito, de $1 \mathrm{~cm}$ de altura, en la pared exterior, dentro de una de las bandas pintadas que forman parte de la decoración de la pieza. Se lee hasta la fractura: $++H+$.

\subsubsection{Anepigráficos}

Este grupo de 34 piezas grafitadas con marcas variopintas sigue patrones estadísticos muy parejos a los del conjunto epigrafiado, en cuanto a tipos y formas cerámicas que sirvieron de soporte para las incisiones, así como en la localización puntual de las mismas sobre las superficies cerámicas. Destacan por su frecuencia signos como las $\mathrm{V}$, las $\mathrm{X}$ o las cruces y los asteriscos, aunque también constata-

55 SOLIN, H, Die Griechischen ..., p. 1174.

56 KAJANTO, I., The Latin cognomina ..., pp. 88-89.

57 SOLIN, H, Die Griechischen ..., p. 1658.

58 Ídem, p.1245.

59 HEp 5, 815; Oliva, Valencia.. Además en Mérida conocemos tres lucernas con sigilla del taller de Strobilus (cf. RODRÍGUEZ MARTÍN, G., Lucernas romanas..., pp.176-177; figura XXV, 56 y 57). 
mos la presencia de hojas de palma, varios numerales (con reservas), una esvástica o cruz gamada, etc. (Tabla 2, núm. 89-122); motivos todos ellos recurrentes en otros repertorios consultados. ${ }^{60}$ La consideración que han recibido esta clase de grafitos por algunos autores, aparte de la finalidad discriminatoria de cada pieza dentro de un conjunto con pluralidad de propietarios, es como signos apotropaicos o profilácticos 0 , simplemente, como mera distracción lúdica. ${ }^{61}$

\section{En paredes finas emeritenses}

89. Vaso. Fragmento correspondiente a la base de un vaso de paredes finas emeritenses, que presenta un grafito en el fondo exterior, en el centro del anillo que forma el pie. Se trata de una figura compuesta por un rectángulo de $2 \times 1 / 1,5 \mathrm{~cm}$ que encierra una cruz, mientras que uno de sus lados largos sirve de base para un triángulo isósceles, con uno de sus lados redondeado debido al relieve circular torneado de la superficie cerámica.

90. Copa. Fragmento del cuerpo de un copa de paredes finas emeritenses que conserva parte de un grafito en la pared exterior. Parece tratarse de una marca en forma de asterisco.

91. Jarra. Fragmento correspondiente a la base de una jarra de paredes finas emeritenses, que presenta grafito grabado con incisión profunda en el fondo exterior, en el centro del anillo que forma el pie. Podría ser una $\mathrm{T}$ de $1 \mathrm{~cm}$ de altura o tal vez una marca sencilla formada por dos trazos rectos que se cruzan.

\section{En terra sigillata gálica}

92. Drag. 15/17. Fragmento del borde y del cuerpo de un plato de terra sigillata gálica, forma Drag. 15/17, en el que se ha grabado una marca grafitada de 0,8 $\mathrm{cm}$ de altura en la pared exterior, muy cerca del borde. Parece tratarse de una figura esquemática de difícil interpretación.

93. Drag. 15/17. Fragmento de la base y del cuerpo de un plato de terra sigillata gálica, forma 15/17, con sello de taller partido, que porta una marca grafitada en forma de $\mathrm{V}$, de $2,1 \mathrm{~cm}$ de altura, en la base exterior, dentro del anillo del pie.

94. Drag. 15/17. Fragmento correspondiente a la mitad de la base de un plato de terra sigillata gálica, forma Drag. 15/17 con sigillum Sabinvs. Porta grafito de 1,5 $\mathrm{cm}$ de altura, en la base al exterior, dentro del anillo del pie, que consiste en una marca en forma de $\mathrm{V}$.

60 ABASCAL PALAZÓN, J.M. y CEBRIÁN FERNÁNDEZ, R., «Grafitos cerámicos de Segobriga (1997-2006)», Lvcentvm, XXVI, (2008), p.171. OZCÁRIZ GIL, P. y UNZU URMENETA, M., "Grafitos figurativos, palmas, tridentes y otros signos en cerámica romana de la plaza del Castillo de Pamplona», Príncipe de Viana (PV), 253, (2011), pp. 79-95. CARRETERO VAQUERO, S., «Grafitos del campamento romano de Petavonium (Rosinos de Vidriales, Zamora)», Brigecio, 8, (1998), p.61. RODRÍGUEZ MARTÍN, F.G. y JEREZ LINDE, J.M., Notas para la clasificación de los grafitos..., láminas IV-VIII y XI-XV.

61 CARRETERO VAQUERO, S., Grafitos del campamento..., pp. 49-50. 
95. Drag. 18. Fragmento de base de un plato de terra sigillata gálica, forma Drag. 18, que conserva en su fondo interior una serie de marcas grafitadas consistentes en cruces y rayas sin orden aparente alguno.

96. Drag. 18. Fragmento de la base de un plato de terra sigillata gálica, forma Drag. 18, que conserva partido grafito en el fondo exterior, dentro del anillo del pie. Se aprecia una secuencia de cinco trazos rectos en batería y otro en diagonal que los cruza. Apostamos por una marca anepígrafa de interpretación dudosa, tal vez de carácter numérico.

97. Plato. Fragmento de la base de un plato de terra sigillata gálica, con sigiIlum ilegible, que conserva marca grafitada en forma de $\mathrm{V}$, de $2 \mathrm{~cm}$ de altura, en el fondo exterior, dentro del anillo del pie.

98. Plato. Fragmento de base de un plato de terra sigillata gálica, forma indeterminada, que conserva parte de un grafito en el fondo exterior dentro del anillo del pie. Son dos trazos rectos formando un ángulo agudo: tal vez de una marca en forma de $\mathrm{V}$, tal vez de una letra como $\mathrm{A}, \mathrm{N}$ o $\mathrm{M}$.

99. Drag. 24/25. Fragmento de base y de la parte inferior del cuerpo de una copa de terra sigillata gálica, forma Drag. 24/25, con sigillum posiblemente de Masculus abreviado. Presenta marca grafitada en forma de asterisco en el fondo exterior dentro del anillo del pie.

100. Drag. 24/25. Fragmento correspondiente a la base de una copa de terra sigillata gálica, forma Drag. 24/25, con sigillum Albinus. En el fondo exterior, dentro del anillo del pie, se grabó una marca grafitada, de $3,1 \mathrm{~cm}$ de diámetro, que representa una cruz gamada. El mismo símbolo aparece esgrafiado en un cuenco de terra sigillata hispánica, forma 37 , hallado en Mérida. ${ }^{62}$

101. Drag. 24/25. Copa de terra sigillata gálica, forma Drag. $24 / 25$, con sigillum ilegible del taller, que porta grafito de 2,2 cm de altura en la pared exterior, en su zona lisa comprendida entre la carena y el pie. El grafito se debió grabar con la pieza puesta boca abajo. Proponemos la lectura de XV nexadas. Podría ser la indicación de un numeral o simplemente una marca compuesta por los trazos de una cruz y una $\mathrm{V}$.

102. Drag. 24/25. Fragmento de la base y del perfil completo de una copa de terra sigillata gálica, forma Drag. 24/25, con sigillum con doble impresión ilegible. Conserva fracturado un grafito en la base al exterior dentro del anillo del pie. Consiste en una cruz y una palabra que conserva tres letras de $0,5 \mathrm{~cm}$ de altura, incisas entre dos de las aspas de la cruz. Su lectura e interpretación resulta arriesgada por los rayones que ha sufrido la superficie cerámica: VII (?). Podría ser un indicativo numérico o una abreviación onomástica, con $E$ formada por dos astas verticales: $\operatorname{Ve}(---)$.

62 Cf. MAYET, F., Les céramiques sigillées hispaniques..., p.103, ํㅡㄴ 299, planche CCXXXVII. 
103. Drag. 27. Fragmento correspondiente a la base y a parte del cuerpo de una copa de terra sigillata gálica, forma Drag. 27, con sello ilegible del taller, que presenta marca grafitada en forma de $\mathrm{V}$, grabada en el fondo exterior dentro del anillo del pie.

104. Drag. 27. Fragmento que conserva el perfil completo de una copa de terra sigillata gálica, forma Drag. 27, con sigillum roto del taller de Vitalis. Tiene una marca grafitada en forma de cruz, grabada en el fondo exterior, dentro del anillo del pie.

105. Drag. 27. Fragmento del cuerpo y de la base de una copa de terra sigillata gálica, forma Drag. 27, con sigillum roto del taller de Lucius o de Lucceius, que conserva tres marcas grafitadas, dos de ellas en la pared exterior, junto al pie, y la tercera que sólo conserva un trazo en el fondo exterior dentro del anillo del pie. Se trata de cruces a las que se han añadido otros trazos aparentemente aleatorios.

106. Drag. 27. Fragmento del cuerpo de una copa de terra sigillata gálica, forma Drag. 27, con grafito de $0,9 \mathrm{~cm}$ de altura, situado en la pared exterior muy próximo al anillo del pie. Parece tratarse de una marca formada por trazos rectos, uno horizontal y dos verticales. Si se hubieran grabado las incisiones con la pieza boca abajo, podría interpretarse como la letra griega pi.

107. Drag. 27. Un fragmento correspondiente a la base de una copa de terra sigillata gálica, forma Drag. 27, con sigillum de doble impresión de Severus. Porta grafito de $1,4 \mathrm{~cm}$ de altura máxima en el fondo exterior, dentro del anillo del pie. Consiste en dos trazos rectos paralelos y, apoyándose sobre uno de ellos, una forma ovalada o arqueada dibujada mediante tres trazos. Desconocemos si el autor del grafito ha querido personalizar la pieza con un epígrafe o con alguna suerte de marca figurativa.

108. Drag. 37. Fragmento de base de un cuenco de terra sigillata gálica, forma Drag. 37, que presenta una marca grafitada en forma de cruz, grabada en el fondo interior.

\section{En terra sigillata hispánica}

109. Hisp. 15-17. Fragmento correspondiente a la base de un plato de terra sigillata hispánica, forma 15/17, que conserva varias marcas grafitadas en forma de cruces en el fondo interior.

110. Hisp. 15/17. Fragmento de la base de un plato de terra sigillata hispánica, forma 15-17, que conserva marcas grafitadas en el fondo exterior, dentro del anillo del pie y también junto al mismo anillo pero fuera. Las primeras son una sucesión de cruces dispuestas sin aparente orden. Junto al pie, fuera del anillo, se trazó una cruz, de mayores dimensiones que las anteriores, cerrada con un trazo vertical por uno de sus lados.

111. Hisp. 15/17. Fragmento con el perfil completo de un plato de terra sigillata hispánica, forma $15 / 17$, con sigillum OF.PA.B.L.G.P.R?, que conserva dos marcas grafitadas, de $2 \mathrm{~cm}$ de altura, en forma $V$, en la base exterior de la pieza, 
entre la carena y el pie. Una tiene el ángulo hacia arriba y la otra hacia abajo. Entre ambas hay una separación de $4 \mathrm{~cm}$.

112. Hisp. 24-25. Fragmento de base de una copa de terra sigillata hispánica, forma 24-25, que conserva grafito postcocción de $2 \mathrm{~cm}$ de altura en el fondo interior. Debido a la fractura sufrida sólo se lee el final o el principio del grafito, compuesto por un trazo curvo, como de una $\mathrm{C}$, y otro recto que parte en diagonal de uno de los extremos del anterior. Aventurar una interpretación resulta arriesgado.

113. Hisp. 27. Fragmento correspondiente a la base de una copa de terra sigillata hispánica, forma 27, con sello del taller de Cantaber, que porta grafito en forma de cruz de $2 \mathrm{~cm}$ de altura, grabado en el fondo exterior, dentro del anillo del pie.

114. Hisp. 27. Fragmento del borde y del cuerpo de una copa de terra sigillata hispánica, forma 27 , que conserva marca grafitada en forma de cruz, grabada en la pared interior, próxima al borde.

115. Hisp. 29. Fragmento de base de un cuenco de terra sigillata hispánica, forma 29, que presenta en su fondo interior y exterior sendas marcas grafitadas. La marca exterior, grabada dentro del anillo del pie en el centro, es una cruz latina regular, mientras que la marca interior parece más bien un asterisco trazado con poca precisión.

116. Andújar 1. Fragmento de la base y del cuerpo de un cuenco de terra sigillata hispánica, Andj. 1, que conserva un pequeño trazo recto de un grafito, grabado en el fondo exterior dentro del anillo del pie. Podría ser parte de una de las aspas de una cruz, aunque tal vez también un signo epigráfico.

117. Andújar 1. Fragmento de base de un cuenco de terra sigillata hispánica con marca grafitada en forma de asterisco, grabada en el fondo exterior dentro del anillo del pie.

118. Andújar 1. Fragmento de base de un cuenco de terra sigillata hispánica, con decoración metopada, que porta marca grafitada en el fondo exterior, dentro del anillo del pie. Se trata de una figura cuadrangular de $1,5 \mathrm{~cm}$ de lado.

119. Andújar 1. Fragmento de la base de un cuenco de terra sigillata hispánica, con decoración metopada, que porta grafito en el fondo exterior, dentro del anillo del pie. Se trata de una composición elaborada con cierto geometrismo, con una figura romboidal, en el centro del círculo formado por el anillo del pie, y alrededor de ella varias cruces.

120. Hisp. 37. Fragmento de la base y del cuerpo de un cuenco de terra sigillata hispánica, forma 37, con decoración fitomórfica, que conserva en el fondo exterior, dentro del anillo del pie, un grafito figurativo que representa una palma o espiga. La marca tiene 1,8 $\mathrm{cm}$ de altura. Este motivo es recurrente en todo tipo de cerámicas, sobre todo en las sigillatas. ${ }^{63}$

${ }^{63}$ CARRETERO VAquero, S., Grafitos del campamento..., p. 61. 


\section{En cerámicas comunes}

121. Fragmento de base de una pieza cerrada de cerámica común engobada, que conserva incompleto un grafito en forma de cruz, grabado en el fondo exterior, en el centro del anillo que forma el pie.

122. Fragmento del cuerpo de una botella de cerámica común con superficie exterior engobada, que conserva en la pared exterior parte de una marca grafitada, de $1,8 \mathrm{~cm}$ de altura máxima, consistente en una sucesión de cuatro líneas rectas verticales paralelas entre sí. La fractura de la pieza impide proponer una lectura convincente, pero se podría aventurar una indicación numérica.

\section{CONCLUSIONES}

Con este trabajo se confirmaría que uno de los fines principales de esgrafiar cerámicas de uso cotidiano, con escuetos textos o variados signos, fue la personalización de las vajillas propias para, a buen seguro, diferenciarlas de otras iguales o similares, propiedad de otros individuos integrantes de un mismo colectivo. En un contexto urbano-cultual como en el que nos movemos, es lógico pensar que esta práctica sería habitual entre los moradores familiares de las domus, especialmente entre los grupos de esclavos, como atestigua el análisis onomástico de los restos epigráficos.

Cuantitativamente observamos una proliferación de marcas epigráficas frente a las anepígrafas simples, que podrían darnos indicios de un elevado índice de alfabetización en el lugar en época flavia, hecho ya apuntado en el análisis de otras categorías vasculares, caso de los atramentaria cretariae. ${ }^{64}$

El descubrimiento de este conjunto cerámico ha permitido sacar del anonimato a trece individuos, cuyas vajillas se han conservado lo suficiente como para restituir sus nombres. La mayoría de ellos portan cognomina o nomina unica de raíz latina y bien conocidos en la colonia por otras fuentes epigráficas (p.ej. lulius, Placidi, Silvani, Primigeni, Crescens, lucundi, Fortunatus, Avitus), salvo en el caso del previsible tria nomina $P$ (ublius) Mesge[nius - - -] (no 59), donde por primera vez se documenta en las provincias hispanas un nomen gentilicium como Mescenius. Igualmente, otros representan un hápax no sólo en la antroponimia local, como son los casos de Strobilus ( $n^{\circ}$ 86) y Cinami (no 84), sino también en la peninsular, como Sasa (no 28 y 37) y $\Phi \wedge I ?[--$-]? (no 34), acrecentándose así nuestro conocimiento de la onomástica de origen greco-oriental en Augusta Emerita. Todos estos cognomina son habituales entre individuos de extracción servil.

${ }^{64}$ BUSTAMANTE ÁLVAREZ, M. y BELLO RODRIGO, J.R., «La corriente imitativa cerámica de los alfares de Augusta Emerita: el caso concreto de los atramentaria», Mérida excavaciones arqueológicas, 2004, Memoria, 10, (2007), pp. 534-535; y BUSTAMANTE ÁLVAREZ, M., «La cerámica romana en Augusta Emerita en la época altoimperial. Entre el consumo y la exportación», Serie Ataecina, 7, Mérida, 2011, p. 107-109. 
Además de la importante aportación aplicable al campo de la antroponimia, el estudio de este contexto cerrado nos ha permitido conocer con una mayor precisión el circuito comercial cerámico de estos momentos en Mérida con el apoyo de otros contextos. Así, para la producción local de lucernas, podemos, estratigráficamente hablando, concentrar la producción del alfarero L.F.O en época vespasianea, estando en momentos previos y posteriores ausentes. ${ }^{65}$ De igual modo, la ausencia en este repertorio de uno de los alfareros «emeritenses» 66 más importantes, Gabinia, nos permitiría presuponer una producción posterior en el tiempo.

En lo que respecta al soporte predomina ampliamente las producciones en terra sigillata tanto gálicas como hispánicas, ambas alóctonas a este lugar. Este hecho nos indicaría un deseo expreso por marcar unas piezas «exóticas» y de difícil acceso o bien todo lo contrario, un masivo uso y, por consiguiente, la necesidad imperante de marcarlas en ambientes comunales. Entendemos, por la frecuente aparición de este tipo de piezas, que la opción más acertada es la segunda y esto vendría apoyado por las formas grafitadas - principalmente las parópsides Drag. $24-25$ y 27 y los catinni Drag. 15/17 así como $18-{ }^{67} \mathrm{Si}$ tenemos en cuenta que los servicios principales son las formas referidas, hablamos, por consiguiente, de piezas muy reiterativas en las mesas emeritenses, de ahí esta necesidad.

Cuantitativamente los ejemplares grafitados de sigillatas hispánicas y gálicas son parejos. Este hecho invalidaría la afirmación de Mayet, quien determinó que las piezas hispánicas eran más propicias al grafitado que las itálicas y las sudgálicas, debido a una menor adherencia del barniz hispánico y, por consiguiente, un mejor plasmado del grafito. ${ }^{68}$

Reiteramos que esta metodología de estudio en Mérida es una novedad, siendo nuestro interés continuar esta línea de investigación en un futuro, atendiendo al potencial epigráfico que la capital de la Lusitania nos ofrece.

65 Para evaluar la dinámica comercial del lugar cf. BUSTAMANTE ÁLVAREZ, M., Terra Sigillata Hispánica en Augusta Emerita (Mérida, Badajoz). Valoración tipocronológica a partir de los vertederos del suburbio norte, (Tesis doctoral s.p.), Universidad de Cádiz, 2010.

${ }^{66}$ Lo entrecomillamos pues, aunque la factura es claramente emeritense, hoy en día se duda si estamos ante un diseño local o bien ante un "sobremolde».

${ }_{67}$ BUSTAMANTE ÁLVAREZ, M., Terra Sigillata Hispánica...

${ }^{68}$ MAYET, F., Les céramiques sigillées hispaniques..., pp. 240-241. 


\begin{tabular}{|l|l|}
\hline Texto & № grafito \\
\hline A & 68 \\
\hline AM[-?] & 32 \\
\hline Avitu[s] & 83 \\
\hline C & 65 \\
\hline C•L & 1.2 , 3 y 4 \\
\hline C+[---]? & 30 \\
\hline CA[---]? & 17 \\
\hline CE & 18 \\
\hline Cinami[---]? & 84 \\
\hline CL & 33 y 76 \\
\hline CR+[---]? & 77 \\
\hline Cresc(ens)•f(ecit) & 51 \\
\hline DOM & 74 \\
\hline Dom(i)ni & 52 \\
\hline E & 50 y 53 \\
\hline ERO[---]? & 85 \\
\hline F•O•F & 10 \\
\hline FE & 19 y 49 \\
\hline [F]ortunatus & 82 \\
\hline H & 15 \\
\hline HE & 78 \\
\hline HI & 72 \\
\hline IA[---]? & 56 \\
\hline l•C•G & 9 \\
\hline lucundi & 57 \\
\hline & \\
\hline
\end{tabular}


Grafitos sobre cerámica del puticuli de la calle Cabo Verde...

\begin{tabular}{|l|l|}
\hline lulius & 14 \\
\hline L•F•O & $5,6,7$ y 8 \\
\hline LIC & 75 \\
\hline LV[---]? & 20 \\
\hline M & $35,39,40,54$ y 70 \\
\hline M[---]? & 87 \\
\hline MA[---]? & 21 \\
\hline [Ma]xsvmi[---]? & 67 \\
\hline MI & 38 y 62 \\
\hline ML & 11 y 12 \\
\hline NE & 16 \\
\hline NI & 41 y 63 \\
\hline NIC & 13 \\
\hline Placidi & 22 \\
\hline Plau[t- ---]? & 24 \\
\hline PM & 27 \\
\hline PM[---]? & 34 \\
\hline P(ubli- ) Mesge[ni----] & 59 \\
\hline Primigeni & 36 \\
\hline Q (o P) T A [---]? & 61 \\
\hline R & 42 \\
\hline S & 66 \\
\hline Salv[---]? & 47 \\
\hline SAT & 58 \\
\hline Sasa & 37 \\
\hline Sa[sa]? & 28 \\
\hline [Secu]ndi+[---]? & 71 \\
\hline & \\
\hline
\end{tabular}




\begin{tabular}{|l|l|}
\hline [S]ilvani & 25 \\
\hline [St]robilus & 86 \\
\hline TAN o TAV & 60 \\
\hline TOCTEAI & 23 \\
\hline VA ? & 29 \\
\hline VKDEDORI & 73 \\
\hline [---]? & 34 \\
\hline [---]? +A & 80 \\
\hline++ A+++[---]? & 69 \\
\hline [---]? AL[---]? & 48 \\
\hline [---]bae & 45 \\
\hline [---]? ++C+[---]? & 26 \\
\hline [---]? +cicii & 55 \\
\hline [-]? F & 44 \\
\hline$[---] ?++H+[--] ?$ & 88 \\
\hline$[---] ?$ MII & 64 \\
\hline$[---] ? ~ N F+$ & 43 \\
\hline$[---] ?$ P & 31 \\
\hline$[---]$ rtis & 46 \\
\hline
\end{tabular}

Tabla 1: Índice alfabético de los textos grafitados. 
Grafitos sobre cerámica del puticuli de la calle Cabo Verde...

\begin{tabular}{|c|c|c|c|c|c|c|}
\hline № & 8067- & Tipo & Forma & Grafito & Situación & Cocc. \\
\hline 1 & $65-205$ & CLAI (Lucerna) & Dr. 11 & $C \cdot L$ & Base & Pre \\
\hline 2 & $65-696$ & CLAI (Lucerna) & Dr. 9 & $C \cdot L$ & Base & Pre \\
\hline 3 & $65-265$ & CLAI (Lucerna) & ¿? & $C \cdot L$ & Base & Pre \\
\hline 4 & $65-666$ & CLAI (Lucerna) & ¿? & $C \cdot L$ & Base & Pre \\
\hline 5 & $22-445$ & CLAI (Lucerna) & ¿Dr. 9 ? & $L \cdot F \cdot O$ & Base & Pre \\
\hline 6 & $65-699$ & CLAI (Lucerna) & ¿? & $L \cdot F \cdot O$ & Base & Pre \\
\hline 7 & $65-697$ & CLAI (Lucerna) & ¿? & $L \cdot F \cdot O$ & Base & Pre \\
\hline 8 & $65-700$ & CLAI (Lucerna) & ¿? & $L \cdot F \cdot O$ & Base & Pre \\
\hline 9 & $65-224$ & CLAI (Lucerna) & Dr. 9 & $\mid \cdot C \cdot G$ & Base & Pre \\
\hline 10 & $65-701$ & CLAI (Lucerna) & ¿? & $\mathrm{F} \cdot \mathrm{O} \cdot \mathrm{F}$ & Base & Pre \\
\hline 11 & $21-496$ & CLAI (Lucerna) & ¿? & $M[L] ?$ & Base & Pre \\
\hline 12 & $21-514$ & CLAI (Lucerna) & ¿? & $\mathrm{ML}$ & Base & Pre \\
\hline 13 & $65-698$ & CLAI (Lucerna) & ¿? & ---]? NIC & Base & Pre \\
\hline 14 & $65-257$ & CLAI (Lucerna) & Dr. 9 & IVLIVS & Base & Pre \\
\hline 15 & $65-667$ & cerám.engobada & Lucerna & $\mathrm{H}$ & Base & Pre \\
\hline 16 & $65-195$ & CLAI (Lucerna) & Den. VA & $\mathrm{NII}$ & Base+Disco & Post \\
\hline 17 & $65-641$ & TS Itálica & Consp.24 & CA[---? & Base & Post \\
\hline 18 & $22-429$ & TS Gálica & $15 / 17$ & CE & Base & Post \\
\hline 19 & $65-657$ & TS Gálica & $15 / 17$ & FII & Base & Post \\
\hline 20 & $65-646$ & TS Gálica & $15 / 17$ & LV[---? & Base & Post \\
\hline 21 & $65-651$ & TS Gálica & $15 / 17$ & MA[---? & Base & Post \\
\hline 22 & $21-494$ & TS Gálica & 18 & PLACIDI & Base & Post \\
\hline 23 & $22-428$ & TS Gálica & 18 & TOCTEAI & Pared & Post \\
\hline 24 & $22-430$ & TS Gálica & 18 & PLAV[T---? & Base & Post \\
\hline 25 & $22-432$ & TS Gálica & 18 & [S]ILVANI & Base & Post \\
\hline 26 & $65-654$ & TS Gálica & 18 & $---] ?++\mathrm{C}+[---?$ & Base & Post \\
\hline
\end{tabular}




\begin{tabular}{|c|c|c|c|c|c|c|}
\hline 27 & $21-503$ & TS Gálica & 18 & PM & Base & Post \\
\hline 28 & $65-638$ & TS Gálica & 18 & $\mathrm{SA}[\mathrm{SA}] ?$ & Base & Post \\
\hline 29 & $22-441$ & TS Gálica & 18 & ¿VA? & Base & Post \\
\hline 30 & $65-652$ & TS Gálica & 18 & $\mathrm{C}+[---?$ & Pared & Post \\
\hline 31 & $65-706$ & TS Gálica & 18 & $---]$ ? P & Base & Post \\
\hline 32 & $65-717$ & TS Gálica & $24-25$ & AM[-? & Base & Post \\
\hline 33 & $65-417$ & TS Gálica & $24-25$ & $\mathrm{CL}$ & Pared & Post \\
\hline 34 & $65-711$ & TS Gálica & $24-25$ & PM ० ФАI[--- & Base & Post \\
\hline 35 & $65-710$ & TS Gálica & $24-25$ & $M$ & Base & Post \\
\hline 36 & $65-650$ & TS Gálica & 27 & PRIMIGIINI & Base & Post \\
\hline 37 & $65-637$ & TS Gálica & 27 & SASA & Base & Post \\
\hline 38 & $21-502$ & TS Gálica & 27 & MI & Base & Post \\
\hline 39 & $65-655$ & TS Gálica & 27 & M & Base & Post \\
\hline 40 & $65-636$ & TS Gálica & 27 & M & Pared & Post \\
\hline 41 & $65-635$ & TS Gálica & 27 & $\mathrm{NI}$ & Base & Post \\
\hline 42 & $65-649$ & TS Gálica & 27 & $\mathrm{R}$ & Base & Post \\
\hline 43 & $65-704$ & TS Gálica & 27 & ---]? NF+ & Base & Post \\
\hline 44 & $65-707$ & TS Gálica & 27 & -]? F & Base & Post \\
\hline 45 & $21-495$ & TS Gálica & 27 & ---]BAE & Pared & Post \\
\hline 46 & $65-648$ & TS Gálica & 27 ó $24-25$ & ---]RTIS & Base & Post \\
\hline 47 & $65-643$ & TS Gálica & 29 & SALV[---? & Base & Post \\
\hline 48 & $1-1$ & TS Gálica & 33 & ---]¿AL? [--- & Pared & Post \\
\hline 49 & $65-639$ & TS Gálica & 37 & FE & Base & Post \\
\hline 50 & $21-509$ & TS Gálica & 37 & $E$ & Base & Post \\
\hline 51 & $65-647$ & TS Hispánica & $15 / 17$ & $\mathrm{CRESC} \cdot \mathrm{F}$ & Base & Post \\
\hline 52 & $65-642$ & TS Hispánica & $15 / 17$ & DOMNI & Base & Post \\
\hline 53 & $94-3$ & TS Hispánica & $15 / 17$ & ¿VI? / E & Base & Post \\
\hline
\end{tabular}


Grafitos sobre cerámica del puticuli de la calle Cabo Verde...

\begin{tabular}{|c|c|c|c|c|c|c|}
\hline 54 & $00-1$ & TS Hispánica & $15 / 17$ & $\mathrm{M}$ & Base & Post \\
\hline 55 & $65-713$ & TS Hispánica & $15 / 17$ & ---]? +CICll & Base & Post \\
\hline 56 & $21-497$ & TS Hispánica & $15 / 17$ & $\mathrm{IA}[---? /--]$ ? VI & Base & Post \\
\hline 57 & $65-712$ & TS Hispánica & 27 & IVCVNDI & Base & Post \\
\hline 58 & $22-433$ & TS Hispánica & 27 & SAT & Base & Post \\
\hline 59 & $22-425$ & TS Hispánica & 27 & PMIISGII[NI--- & Pared & Post \\
\hline 60 & $65-644$ & TS Hispánica & 27 ó $24 / 25$ & TAV vel TAN & Pared & Post \\
\hline 61 & $65-722$ & TS Hispánica & 27 & QTA vel PTA[--? & Base & Post \\
\hline 62 & $94-1$ & TS Hispánica & 27 & MI & Base & Post \\
\hline 63 & $22-427$ & TS Hispánica & 27 & NI[--- ? & Pared & Post \\
\hline 64 & $22-423$ & TS Hispánica & 27 & ---] ? MII & Pared & Post \\
\hline 65 & $21-508$ & TS Hispánica & 27 & $\mathrm{C}$ & Base & Post \\
\hline 66 & $22-437$ & TS Hispánica & 27 & $S$ & Base & Post \\
\hline 67 & $65-716$ & TS Hispánica & 27 & MA]XSVMI[--- ? & Base & Post \\
\hline 68 & $65-663$ & TS Hispánica & 27 & $\mathrm{~A} /++$ & Pared & Post \\
\hline 69 & $65-653$ & TS Hispánica & 27 & $++\mathrm{A}+++[---?$ & Pared & Post \\
\hline 70 & $21-510$ & TS Hispánica & 27 & ¿M? & Base & Post \\
\hline 71 & $22-442$ & TS Hispánica & 33 ó 46 & SECV]NDI+[--- ? & Pared & Post \\
\hline 72 & $65-645$ & TS Hispánica & 35 & $\mathrm{HI}$ & Pared & Post \\
\hline 73 & $65-640$ & TS Hispánica & 37 & VKDEDORI & Base & Post \\
\hline 74 & $22-434$ & TS Hispánica & 37 & DOM & Fondo & Post \\
\hline 75 & 21-499 & TS Hispánica & 37 & $\mathrm{LIC} \circ \mathrm{IIC} / \mathrm{G}[---?$ & Pared & Post \\
\hline 76 & $22-424$ & TS Hispánica & 37 & $\mathrm{CL}$ & Base & Post \\
\hline 77 & $21-504$ & TS Hispánica & 37 & $\mathrm{CR}+[---?$ & Pared & Post \\
\hline 78 & $21-493$ & TS Hispánica & 37 & $\mathrm{HE}$ & Base & Post \\
\hline 79 & $94-4$ & TS Hispánica & 37 & $---] ?+\mathrm{MA} \bullet+---?$ & Pared & Post \\
\hline 80 & $65-720$ & TS Hispánica & 37 & $---] ?+A$ & Pared & Post \\
\hline
\end{tabular}




\begin{tabular}{|c|c|c|c|c|c|c|}
\hline 81 & $22-435$ & TS Hispánica & 37 & $?$ & Base & Post \\
\hline 82 & $22-426$ & Cerámica común & ¿Botella? & [F]ORTVNATVS & Pared & Post \\
\hline 83 & $21-498$ & Cerámica común & Olla & AVITV[S] & Borde & Post \\
\hline 84 & $21-505$ & Cerámica común & Escudilla & CINAMI[---? & Borde & Post \\
\hline 85 & $94-2$ & Cerámica común & Olla & ERO[---? & Pared & Post \\
\hline 86 & $21-500$ & Cerámica común & $?$ & [ST]ROBILVS & Pared & Post \\
\hline 87 & $22-443$ & Cerámica común & Olla & $\mathrm{M}[---?$ & Borde & Post \\
\hline 88 & $65-668$ & Cerámica pintada & Botella & $---] ?++\mathrm{H}+[---?$ & Pared & Post \\
\hline 89 & $65-665$ & PP.FF.EE & Vaso & Marca geométrica & Base & Post \\
\hline 90 & $56-1$ & PP.FF.EE & Copa & Asterisco & Pared & Post \\
\hline 91 & $65-664$ & PP.FF.EE & Jarra & $\mathrm{T}$ & Base & Post \\
\hline 92 & $21-507$ & TS Gálica & $15 / 17$ & Marca? & Pared & Post \\
\hline 93 & $65-702$ & TS Gálica & $15 / 17$ & V & Base & Post \\
\hline 94 & $21-501$ & TS Gálica & $15 / 17$ & V & Base & Post \\
\hline 95 & $65-656$ & TS Gálica & 18 & Cruces & Fondo & Post \\
\hline 96 & $65-718$ & TS Gálica & 18 & Rayas & Base & Post \\
\hline 97 & $65-703$ & TS Gálica & Plato & V & Base & Post \\
\hline 98 & $65-705$ & TS Gálica & Plato & ¿V? & Base & Post \\
\hline 99 & $65-658$ & TS Gálica & $24 / 25$ & Asterisco & Base & Post \\
\hline 100 & $65-708$ & TS Gálica & $24 / 25$ & Esvástica & Base & Post \\
\hline 101 & $65-714$ & TS Gálica & $24 / 25$ & $X V$ & Pared & Post \\
\hline 102 & $22-431$ & TS Gálica & $24 / 25$ & $\mathrm{X}$ et VII & Base & Post \\
\hline 103 & $65-660$ & TS Gálica & 27 & V & Base & Post \\
\hline 104 & $22-436$ & TS Gálica & 27 & $\mathrm{X}$ & Base & Post \\
\hline 105 & $21-511$ & TS Gálica & 27 & Cruces & Pared+Base & Post \\
\hline 106 & $22-440$ & TS Gálica & 27 & $\Pi$ & Pared & Post \\
\hline 107 & $65-709$ & TS Gálica & 27 & Marca? & Base & Post \\
\hline
\end{tabular}


Grafitos sobre cerámica del puticuli de la calle Cabo Verde...

\begin{tabular}{|l|l|l|l|l|l|l|}
\hline 108 & $65-659$ & TS Gálica & 37 & X & Fondo & Post \\
\hline 109 & $22-444$ & TS Hispánica & $15 / 17$ & Cruces & Fondo & Post \\
\hline 110 & $65-721$ & TS Hispánica & $15 / 17$ & Cruces & Base & Post \\
\hline 111 & $21-506$ & TS Hispánica & $15 / 17$ & V V & Base & Post \\
\hline 112 & $65-715$ & TS Hispánica & $24-25$ & Marca ? & Fondo & Post \\
\hline 113 & $21-513$ & TS Hispánica & 27 & X & Base & Post \\
\hline 114 & $22-439$ & TS Hispánica & 27 & X & Pared & Post \\
\hline 115 & $65-661$ & TS Hispánica & 29 & Cruz / Asterisco & Base/Fondo & Post \\
\hline 116 & $65-662$ & TS Hispánica & Andújar 1 & ¿X ? & Base & Post \\
\hline 117 & $22-438$ & TS Hispánica & Andújar 1 & Asterisco & Base & Post \\
\hline 118 & $21-512$ & TS Hispánica & Andújar 1 & Marca geométrica & Base & Post \\
\hline 119 & $65-719$ & TS Hispánica & Andújar 1 & Rombo y cruces & Base & Post \\
\hline 120 & $65-453$ & TS Hispánica & 37 & Palma & Base & Post \\
\hline 121 & $65-669$ & Cerámica común & $?$ & X & Base & Post \\
\hline 122 & $21-515$ & Cerámica común & Botella & ¿Numeral ? & Pared & Post \\
\hline
\end{tabular}

Tabla 2: Cuadro-síntesis de las piezas estudiadas, con su no de orden (№ X) y $n^{\circ}$ de inventario (8067-X-X), tipología y forma del soporte; el grafito, su situación y momento de grabación (Precocción / Post-cocción). Significado de abreviaturas más usadas: CLAI = cerámica local de acabado irisado, PP.FF.EE. = paredes finas emeritenses, $T S=$ terra sigillata . 


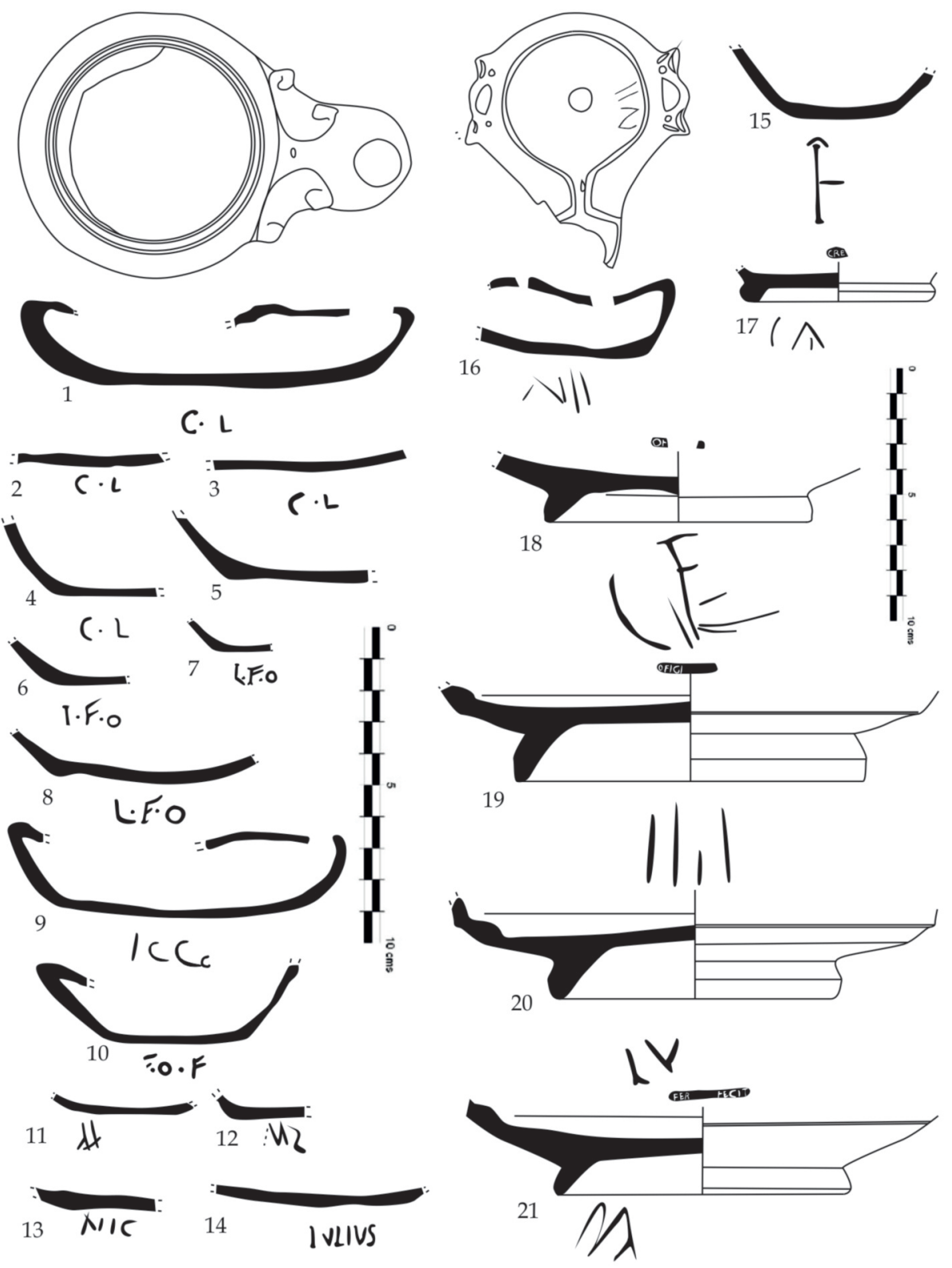

Figura 1.- Representación gráfica de los grafitos y soportes (n. 1-21). 


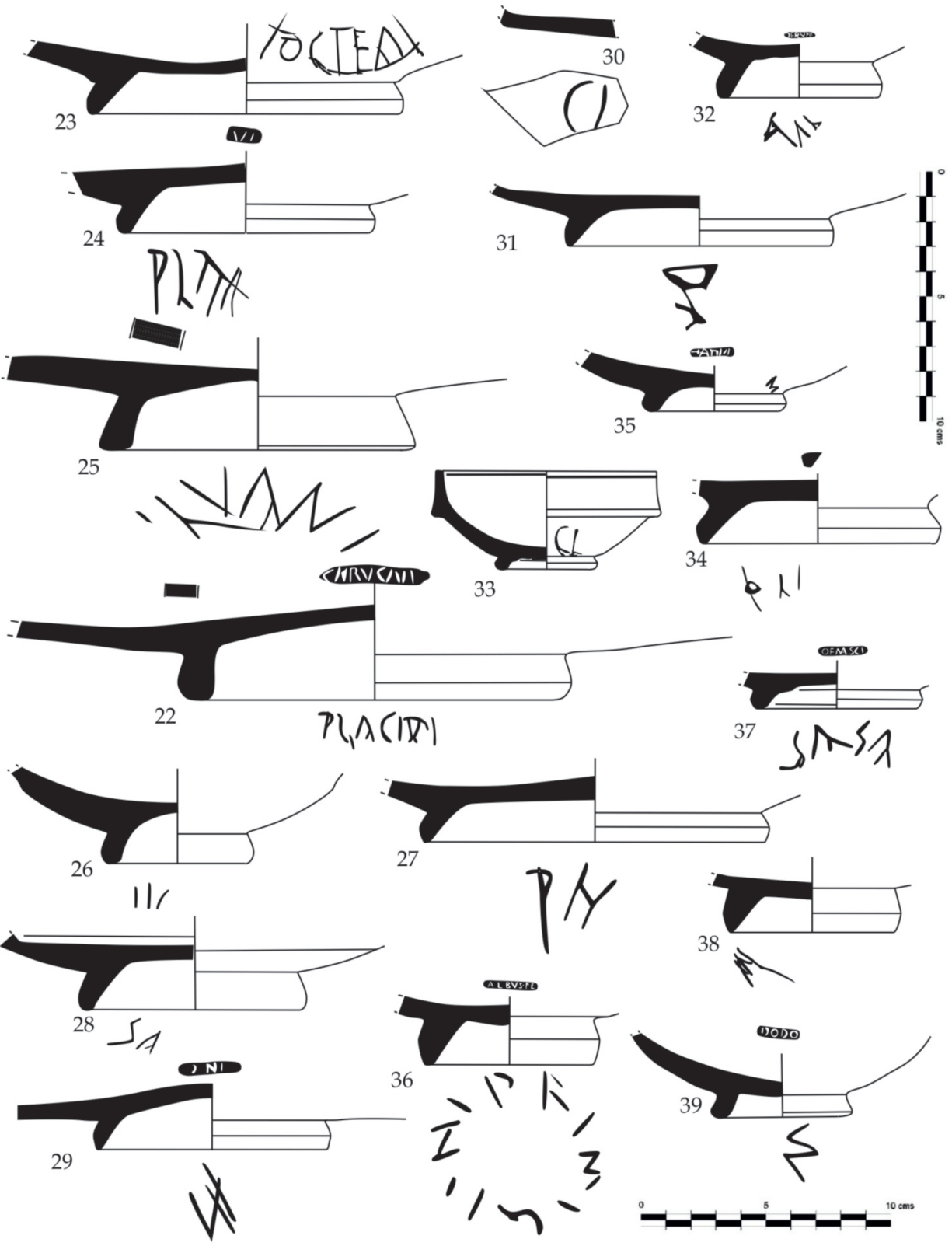

Figura 2.- Representación gráfica de los grafitos y soportes (n. 22-39). 


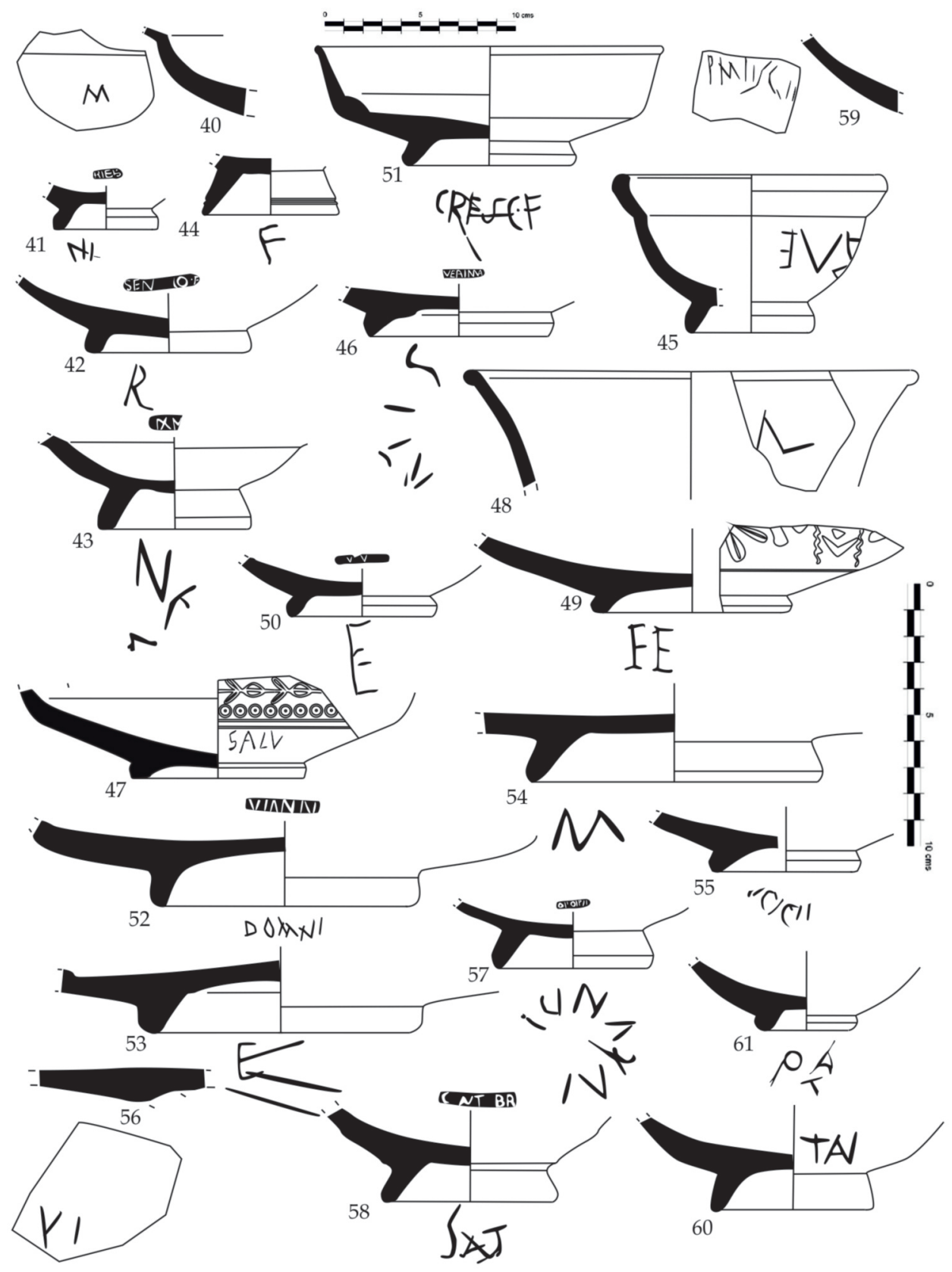

Figura 3.- Representación gráfica de los grafitos y soportes (n. 40-61). 


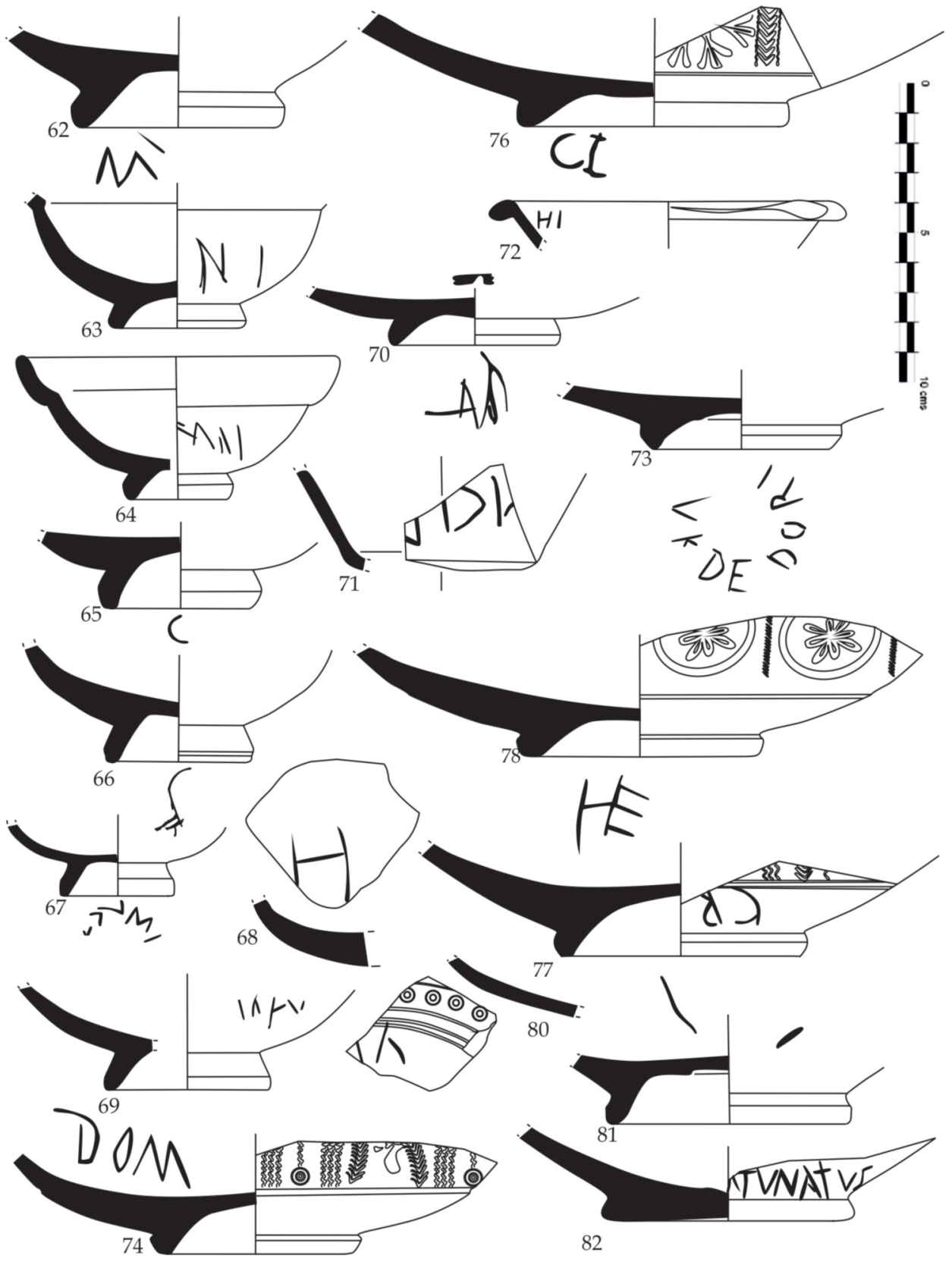

Figura 4.- Representación gráfica de los grafitos y soportes (n. 62-74, 76-78 y 80-82). 


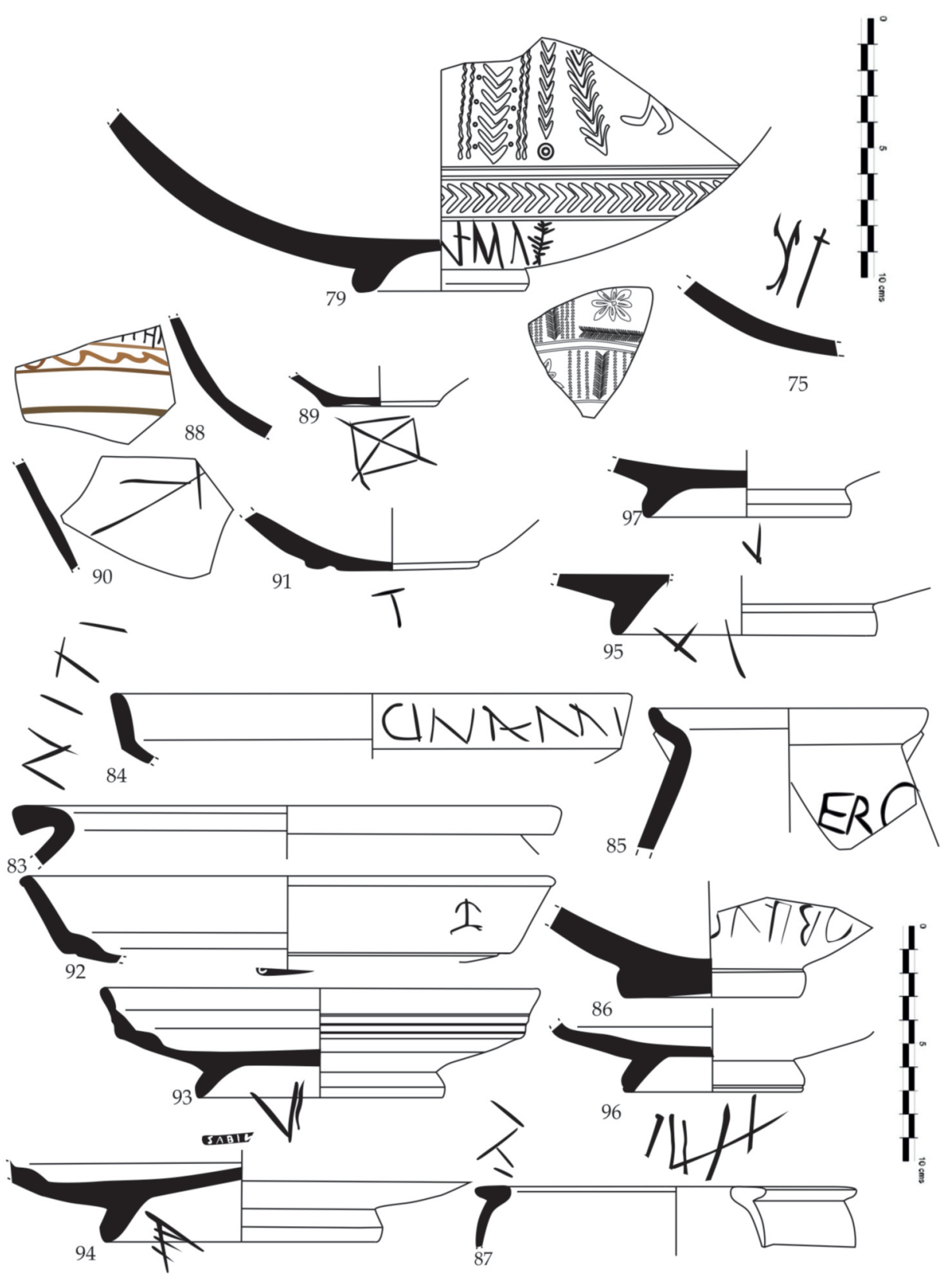

Figura 5.- Representación gráfica de los grafitos y soportes (n. 75, 79 y 83-97). 


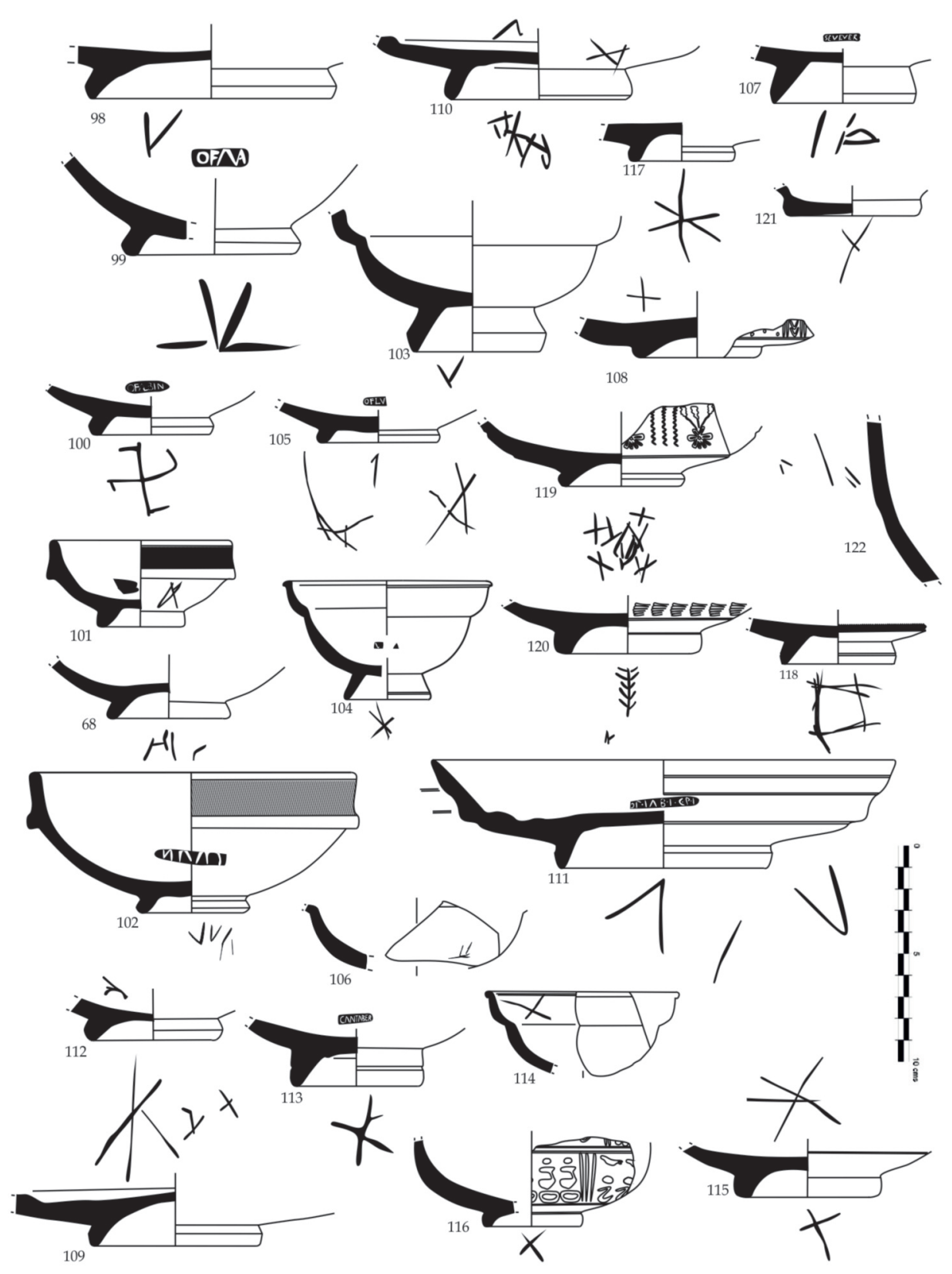

Figura 6.- Representación gráfica de los grafitos y soportes (n. 98-122). 
